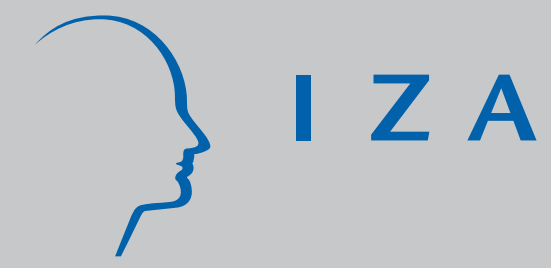

IZA DP No. 10177

Earnings Exemptions for Unemployed Workers:

The Relationship between Marginal Employment, Unemployment Duration and Job Quality

Marco Caliendo

Steffen Künn

Arne Uhlendorff

August 2016 


\title{
Earnings Exemptions for Unemployed Workers: The Relationship between Marginal Employment, Unemployment Duration and Job Quality
}

\author{
Marco Caliendo \\ University of Potsdam, IZA, DIW and IAB \\ Steffen Künn \\ Maastricht University and IZA \\ Arne Uhlendorff \\ CNRS, CREST, IAB, IZA and DIW \\ Discussion Paper No. 10177 \\ August 2016 \\ IZA \\ P.O. Box 7240 \\ 53072 Bonn \\ Germany \\ Phone: +49-228-3894-0 \\ Fax: +49-228-3894-180 \\ E-mail: iza@iza.org
}

\begin{abstract}
Any opinions expressed here are those of the author(s) and not those of IZA. Research published in this series may include views on policy, but the institute itself takes no institutional policy positions. The IZA research network is committed to the IZA Guiding Principles of Research Integrity.

The Institute for the Study of Labor (IZA) in Bonn is a local and virtual international research center and a place of communication between science, politics and business. IZA is an independent nonprofit organization supported by Deutsche Post Foundation. The center is associated with the University of Bonn and offers a stimulating research environment through its international network, workshops and conferences, data service, project support, research visits and doctoral program. IZA engages in (i) original and internationally competitive research in all fields of labor economics, (ii) development of policy concepts, and (iii) dissemination of research results and concepts to the interested public.
\end{abstract}

IZA Discussion Papers often represent preliminary work and are circulated to encourage discussion. Citation of such a paper should account for its provisional character. A revised version may be available directly from the author. 


\section{ABSTRACT}

\section{Earnings Exemptions for Unemployed Workers: The Relationship between Marginal Employment, Unemployment Duration and Job Quality*}

In some countries including Germany unemployed workers can increase their income by working a few hours per week. The intention is to keep unemployed job seekers attached to the labour market and to increase their job-finding probabilities. To analyze the unemployment dynamics of job seekers with and without marginal employment, we consider an inflow sample into unemployment and estimate multivariate duration models. While we do not find any significant impact on the job finding probability in a model with homogeneous effects, models allowing for time-varying coefficients indicate a decreased job finding probability of marginal employment at the beginning of the unemployment spell and an increased job finding probability for the long-term unemployed. Our results suggest that job seekers with marginal employment find more stable post-unemployment jobs, and we find some evidence that the relationship between marginal employment and wages and employment stability varies with respect to skill levels, sector and labor market tightness.

JEL Classification: J64, C41, C33

Keywords: marginal employment, mini-job, unemployment duration, job search, employment stability, multivariate duration models

Corresponding author:

Marco Caliendo

University of Potsdam

Chair of Empirical Economics

August-Bebel-Str. 89

14482 Potsdam

Germany

E-mail: caliendo@uni-potsdam.de

\footnotetext{
* The authors thank Christopher Flinn and two anonymous reviewers for helpful comments and suggestions. We further thank Gerard van den Berg, Bart Cockx, Bo Honore, Bernd Fitzenberger, Bruno Van der Linden, Ralf Wilke and seminar participants at the Berlin Network of Labour Market Research (BeNA), the University of Freiburg, the Paris School of Economics (PSE), the Universite Catolique de Louvain and at the Royal Economic Society 2012 Annual Conference for helpful discussions and comments and Pia Schauerte for excellent research assistance. Marco Caliendo and Arne Uhlendorff thank the German Research Foundation (DFG) for financial support of the project CA 829/1-1. We also thank the Research Data Center (FDZ) of the Federal Employment Agency at the Institute of Employment Research (IAB) for data access. A previous version of this paper circulated as "Marginal Employment, Unemployment Duration and Job Match Quality" (IZA Discussion Paper No. 6499, Bonn).
} 


\section{Introduction}

Unemployment insurance (UI) systems provide benefit payments for unemployed job seekers. The amount of benefits usually depends on previous earnings and declines in accordance with the elapsed unemployment duration. Many studies have shown that more generous benefit schemes correspond with longer unemployment durations, while the empirical evidence of benefit generosity on job match quality is rather mixed and only some studies find positive impacts on post-unemployment outcomes. ${ }^{1}$ In general, UI systems have to strike a balance between the insurance component and the aim of providing the opportunity to search for suitable job matches on the one hand and disincentive effects and moral hazard on the other hand.

Besides a decreasing profile of benefit payments, different strategies exist to increase the outflow probability from unemployment to employment, and to avoid long spells of unemployment. Such strategies comprise active labour market policies (ALMP) including training programs, wage subsidies, start-up subsidies, public employment measures, job search assistance and monitoring schemes (see Card, Kluve, and Weber, 2010, 2015; Kluve, 2010, for recent overviews of the effectiveness of these program types). In some countries, the UI system is characterized by an additional feature: unemployed workers are allowed to work for a few hours per week during their job search and can keep a certain amount of the additional earnings without a reduction in unemployment benefits. Such a policy corresponds to an earnings exemption, which exists in many UI benefits and other social policy programs in Europe and North America, and generally aims to increase labour supply of specific labour market groups. Unemployed workers in Germany have an additional incentive to make use of this earnings exemption due to "marginal employment" (known as a "mini-job" in Germany). This is defined as employment below a certain income threshold where employees are exempted from social security contributions (SSC) and employers pay an overall reduced rate of SSC.

While the intention of such a policy for unemployed workers is to keep them attached to the labour market, its expected effects are ambiguous. On the one hand, marginal employment might increase the probability of taking up a regular job because it may lower human capital deterioration. Moreover, it

\footnotetext{
${ }^{1}$ For example Belzil (2001), Tatsiramos (2009) and Caliendo, Tatsiramos, and Uhlendorff (2013) find evidence for positive impacts while van Ours and Vodopivec (2008) and Card, Chetty, and Weber (2007) find no impact of the generosity of unemployment benefits on job quality.
} 
may be used as a positive screening device or probation period by potential employers before offering a regular job and may increase the probability of receiving job offers due to network effects, i.e., the minijob might serve as a stepping stone to regular employment. On the other hand, the additional income should increase the reservation wage for taking up a regular job, which should prolong the unemployment duration. These effects may have an impact on both, the unemployment duration and the job match quality. Hence, the overall impact of entering marginal employment on subsequent employment outcomes is theoretically ambiguous. It is the aim of this paper to empirically assess the relationship of entering marginal employment and making use of the earnings exemption and the unemployment duration and subsequent job quality of unemployed individuals.

Comparable to the German setting, unemployment insurance systems in Finland, Denmark and France allow unemployed workers to take up a part-time job if they still search for a full-time job. Kyyrä (2010) finds evidence for an increasing transition rate to regular jobs for Finland, while Kyyrä, Parrotta, and Rosholm (2013) find heterogeneous effects on the expected unemployment duration for Denmark. For France, Fremigacci and Terracol (2013) find a negative lock-in effect and an increased transition rate to regular jobs once the unemployed has left the part-time job. Neither of the studies takes postunemployment outcomes into account. However, to investigate this kind of policy it is important to know whether taking up a part-time job or marginal employment during unemployment is related to the subsequent job quality and whether this reduces the probability of re-entering unemployment.

In this paper, we carefully model the dynamic selection of unemployed job seekers into marginal employment by estimating discrete-time duration models for the duration of unemployment and the duration until entering a mini-job and allowing for correlation between these two durations based on unobserved characteristics. We additionally consider the job match quality, i.e. we extend the model by estimating the duration of subsequent employment spells and a wage equation for the initial wage. ${ }^{2}$ We investigate to which extent the relationship between having a mini-job and finding a new job varies with respect to observed characteristics such as age, skill level and the previous working sector, and whether the pattern changes with respect to the elapsed unemployment duration. Our analysis is based on detailed

\footnotetext{
${ }^{2}$ For a similar approach in the context of training programs for unemployed workers see Osikominu (2013), and in the context of sanction effects Arni, Lalive, and van Ours (2013) and van den Berg and Vikström (2014). Jahn and Rosholm (2014) apply a similar method to analyse potential stepping-stone effects of temporary agency employment for unemployed workers.
} 
administrative data for an inflow sample of male workers into unemployment in West Germany in 2001.

Our results suggest that unemployed job seekers with a mini-job have a lower probability of finding a regular job at the beginning of the unemployment spell. However, we find evidence for an increased outflow probability for long-term unemployed workers. Simulations based on the average individual in our sample suggest that after a year of unemployment the expected remaining unemployment duration drops from 16.4 to 15.3 months for job-seekers with a mini-job. Moreover, the jobs taken up by job seekers who entered a mini-job during their unemployment spell are more stable compared to jobs found by individuals without a mini-job. For the average individual the expected employment duration increases from 14.8 to 16.3 months if he entered a mini-job at the beginning of the unemployment spell. We find some evidence for heterogeneous associations between mini-jobs and job search outcomes with respect to observable characteristics: more skilled individuals and individuals who are not working in the construction sector appear to have lower wages if they have taken up a mini-job during unemployment. We find a significantly higher transition probability to regular employment if the mini-job is in the same sector as the previous regular job, and the individual lives in areas characterized by high unemployment rates. For workers living in areas with high unemployment rates, having a mini-job during unemployment also leads to more stable employment spells.

The paper is organized as follows: Section 2 describes the institutional background and surveys relevant previous research. Section 3 presents the data and descriptive statistics. Section 4 describes the econometric approach. The results of the empirical analysis are presented in Section 5, and Section 6 concludes.

\section{Institutional background and related literature}

\section{$2.1 \quad$ Institutional settings}

During our observation period from 2001 to 2004 the unemployment insurance system was characterized by two pillars: unemployment benefits ("Arbeitslosengeld") and means-tested unemployment assistance ("Arbeitslosenhilfe"). Individuals were eligible for unemployment benefits if they were regularly employed subject to social security contributions for at least 12 months within the last three years. The benefit 
level relates to previous average earnings with a replacement rate of $60 \%$ (67\% with children living in the household) of net earnings whereby earnings are capped by the social security contribution assessment ceiling. After the unemployment benefit entitlement expired - which ranges in that period from six to 32 months depending on age and the time spent in employment in the previous seven years - individuals become eligible for means-tested unemployment assistance given they are still searching for a job, with a decreased replacement rate of $53 \%$ ( $57 \%$ with children). There has been no time limit for the receipt of unemployment assistance. In addition to these transfer payments, the unemployed in Germany are allowed to earn additional income through employment. The intention of this earnings exemption is to encourage the unemployed to work for some hours beside being unemployed in order to stay attached to the labour market. Therefore, recipients of unemployment benefit and unemployment assistance are allowed to keep $€ 165 /$ month of additional earnings without suffering a reduction in transfer payments as long as their working time does not exceed 15 hours per week. Earnings above this threshold are fully withdrawn, i.e., earnings exceeding the threshold of $€ 165 /$ month reduce unemployment benefits by the same amount. While having a job increases the income during unemployment, unemployed job seekers have the same access to active labor market programs as unemployed job seekers without a job.

While the German UI system is comparable to many other countries, unemployed individuals in Germany have an additional incentive to work for some hours during unemployment due to the concept of marginal employment, also called "mini-job" (both terms will be used interchangeably throughout the paper). Marginal employment is defined as employment below a certain income level or as temporary employment for a fixed period, and is subject to reduced social security contributions (SSC). The idea of marginal employment was primarily developed in the 1960's as an attempt to increase work incentives for groups with traditionally low labour force participation, including students and housewives/-men, etc. (cf. Rudolph, 1999). Although marginal employment is not restricted to unemployed individuals, it is heavily used by them as the combination of the reduced SSC with the mini-job and the possibility of earnings exemptions within the UI system sets a clear incentive for unemployed job seekers. For 2010 the Federal Employment Agency reports about 7.3 million "mini-jobs", where around two-thirds of these jobs are held by individuals who do not have a regular job (including unemployed workers).

Since 1999, the concept of marginal employment was restricted to a maximum of $€ 325$ per month, 
combined with a working time restriction of 15 hours per week, and temporary employment contracts were restricted to a maximum of two months or 50 working days per year. While employees have been exempted from social security contributions, employers paid only a fixed rate of $22 \%$. In 2003 , the income threshold increased from $€ 325$ to $€ 400$ per month, the working time restriction of 15 hours per week was abolished, and the SSC paid by the employer increased slightly to $23 \%$. It is important to note that the mini-job reform in 2003 had no impact on the situation of unemployed workers. The conditions for additional earnings during the receipt of unemployment benefits, i.e., the exemption rate of $€ 165$ and working time restrictions of 15 hours per week, remained unchanged across the reform in 2003. Caliendo and Wrohlich (2010) do not find any evidence for a significant impact of the reform on the unemployed, which is plausible since the incentive for the unemployed to take up marginal employment did not change within this reform.

It can be summarized that unemployed workers in Germany are allowed to earn additional income while receiving unemployment benefits, and that the concept of marginal employment sets an additional incentive for the unemployed to work for few hours given the reduced pay-roll tax.

\subsection{Potential impacts of marginal employment}

We assume that unemployment is "involuntary" independent of having a mini-job during unemployment or not. This corresponds to the institutional setting, since the receipt of unemployment benefits implies specific job search requirements and - given a suitable job offer - the willingness to take up a regular full-time job. Similar to a job search model allowing for partial benefits presented by Ek and Holmlund (2015), this implies that individuals who receive unemployment benefits have a reservation wage for both types of jobs. The reservation wages depend on observed and unobserved characteristics. Unemployed workers without marginal employment search for a mini-job and for a full-time job simultaneously. The probability of entering a mini-job as well as the probability of entering a full-time job depends on the arrival rate and the reservation wage for the corresponding type of job. In this setting, having a mini-job might have an impact on the probability of receiving a regular job offer, on the search effort and on the reservation wage for a regular job.

On the one hand, marginal employment offers the unemployed job seeker the opportunity to gain 
some work experience during job search and thereby to maintain his professional skills. This effect should be especially relevant if the mini-job is related to the previous sectoral experience. Moreover, having a mini-job should increase the number of job-related contacts. This increase in the network should have a positive impact on the probability of receiving a job offer. A mini-job might also be used as a positive screening device or probation period by potential employers before offering a regular job. To sum up, all of the discussed effects may lead to an increased exit probability from unemployment to regular jobs. On the other hand, there also exist potentially negative effects on the exit probability from unemployment. When having a mini-job, job seekers have less time to search for regular jobs (see Kyyrä, 2010, for a similar argument in the context of partial benefit schemes). The increase in the income increases the utility from unemployment and therewith the reservation wage. These effects should lead to a lower exit probability to regular employment. Besides this effect, the increased income due to marginal employment may allow the unemployed to wait for a better and more stable job, which could decrease the risk of re-entering unemployment. Given these arguments, the overall effect of having a mini-job on job search outcomes is ambiguous.

The existence of earnings exemptions and the possibility to hold a mini-job during unemployment should have an impact on the reservation wage and the search effort for full-time jobs, even for individuals who do not hold a mini-job. In order to investigate the job search behaviour in counterfactual policy designs, one would need to estimate a structural job search model. For this, one would have to model the decision processes in more detail and make corresponding assumptions. This approach goes beyond the scope of this paper. Instead, we are mainly interested in providing reduced form evidence for the unemployment dynamics of unemployed job seekers with and without a mini-job in the current institutional setting. For this, we carefully take the different selection processes into account and flexibly model potential changes of the relationship between having a mini-job and the job finding probability over the duration of unemployment.

\subsection{Related literature}

There exists a number of empirical studies investigating "stepping stone effects" of different employment types to enter regular jobs. In this literature, the estimated relationship between the different employment 
types and the job finding probability is often labeled as "treatment" effect. We estimate similar models as part of this literature. However, we prefer to not use the term "treatment" in this paper, because taking up a mini-job is to a large extent the result of an individual choice and is based on utility maximizing behavior.

An example for a paper investigating stepping stone effects is Cockx and Picchio (2012). They analyse the impact of short-term jobs on subsequent employment outcomes in Belgium based on a multivariate duration model and find evidence for short-term jobs representing a spring-board to long-term jobs. Zijl, van den Berg, and Heyma (2011) find that temporary jobs shorten the unemployment duration in the Netherlands but do not lead to a higher proportion of unemployed workers having regular jobs. Jahn and Rosholm (2014) investigate the impact of temporary agency employment on job search outcomes of unemployed Danish workers and find positive effects especially in tight labour markets.

In Finland, unemployed workers are allowed to take up a part-time or a short full-time job with a duration up to one month whilst receiving unemployment benefits if they continue searching for a fulltime job. Kyyrä (2010) applies a timing-of-events approach and his results suggest that this might have positive effects on the transition rate to regular jobs. He finds evidence for an increasing impact of taking up a short full-time job over the unemployment duration, i.e., for those who take up a short full-time job shortly after entering unemployment the impact does not differ significantly from zero, but it becomes stronger with the elapsed unemployment duration. For part-time jobs he does not find evidence for effect heterogeneity with respect to the elapsed unemployment duration. Within a similar institutional setting in Denmark Kyyrä, Parrotta, and Rosholm (2013) find heterogeneous effects of taking up a part-time job during job search on the expected unemployment duration, for example with respect to age, sex and marital status. Fremigacci and Terracol (2013) find for a similar French program a negative lockin effect for having a subsidized temporary job during unemployment and a positive impact once the unemployed has left the part-time job on the hazard rate to employment. None of the three studies take post-unemployment outcomes into consideration. There exist two studies investigating the effects of marginal employment on subsequent employment outcomes. Freier and Steiner (2008) find that marginal employment leads to a reduction in future unemployment and slightly increases cumulated earnings in Germany; Böheim and Weber (2011) find that marginally employed workers in Austria experience less 
frequent regular employment, more unemployment and lower wages compared to those workers who are not marginally employed. Both studies apply a static propensity score matching approach without taking dynamic selection over time into account.

\section{$3 \quad$ Data and descriptive statistics}

\subsection{Dataset and sample definition}

The empirical analysis uses the IZA/IAB Administrative Evaluation Dataset, which is based on the Integrated Employment Biographies (IEB) provided by the Institute for Employment Research (IAB) and consists of a 5\% random sample of entries into unemployment between 2001 and 2008 in Germany (see Eberle and Schmucker, 2015, for a detailed description of the data). ${ }^{3}$ The IEB are administrative data and contain detailed information on employment subject to social security contributions, unemployment, participation in active labour market policies, wages and transfer payments. The data additionally include a broad range of socio-economic characteristic including education, family status and health restrictions. The data do not contain information about the working hours, periods in self-employment, working as a civil servant, or periods spent in inactivity. From this data we draw a random sample of inflows into unemployment in 2001. The unemployment spell must last at least two weeks and prior to this unemployment entry the individuals have to be employed subject to social security contributions for a minimum duration of three months to ensure that we have a "real" inflow sample into unemployment. Moreover, we exclude individuals who had a mini-job during the three months before entering unemployment because we want to model the selection into this state. We restrict our observation period from 2001 to 2004, since a major reform of the German UI system was introduced in $2005 .^{4}$

The estimation sample is based on male individuals in West Germany. We focus on males because nearly all men work full-time if they have a regular job, whereas part-time work is much more common among females (see e.g. Haan, 2010). With the exclusion of women, we aim to exclude job-seekers with

\footnotetext{
${ }^{3}$ This study is based on a weakly anonymized sample of the IEB by the IAB (V.901). The data can be accessed at the Research Data Center of the Federal Employment Agency at the IAB.

${ }^{4}$ Although the structure and duration of the benefit system changed with the reform, the rules for earnings exemptions remained unchanged (see Caliendo and Hogenacker, 2012). Therefore, we argue that our results are still valid for the current setting of the UI system. We nevertheless decided to stop in 2004 as the benefit system changed systematically leading to significant changes in the average exit rates to employment. Therefore, including the period after 2004 in the analysis would bear the risk that we measure a mixture of the reform and mini-job effect.
} 
preferences for part-time employment. Due to lower income differentials between unemployment with a mini-job and part-time jobs, the hourly reservation wage of individuals looking for part-time jobs should be relatively high. For those job-seekers it might be relative attractive to remain unemployed and increase their income by taking up a mini-job. ${ }^{5}$ Furthermore, the high share of part-timers among women renders an evaluation of wages in the first job after leaving unemployment difficult as we do not observe working hours. Finally, since East and West Germany still differ substantially in terms of economic and labour market indicators during our observation period, we exclude East Germany from the analysis. As we are interested in the transition to regular employment and subsequent job stability, the adverse labour market conditions in East Germany might have distorting effects, making results difficult to interpret and transfer to other countries. Moreover, the share of unemployed individuals entering public employment programs is clearly higher in East than West Germany.

Overall, focusing on men in West Germany leads to a relatively homogeneous estimation sample. We further restrict our sample to men aged between 25 and 55 . The lower age restriction is motivated by the educational system, and the upper by the retirement schemes in Germany. Our final sample thus consists of 24,593 individuals. We follow each individual for 36 months from entry into unemployment onwards. In Germany most of employment spells start at the beginning of a month (and unemployment spells typically last until the end of a month). In our data set, around $60 \%$ of new employment spells start within the first five days of the corresponding month. Therefore, we construct discrete time spell data in which one month corresponds to one time unit.

We define two main mutually exclusive labour market states: unemployment and regular employment. Individuals who are either registered as unemployed at the Federal Employment Office (with or without benefit receipt) or participants in ALMP programs are defined as being unemployed. Parallel to being unemployed, individuals are allowed to take up a mini-job. In this case, the individual occupies two parallel states, i.e., being unemployed and having a mini-job. It is important to note that having a minijob does not change the job search requirements of the unemployment benefit recipients. They are still supposed to search for a full-time job. Individuals with a mini-job parallel to regular employment are

\footnotetext{
${ }^{5}$ This assumption restricts the validity of the results to full-time workers, i.e., we expect the results to be different for job-seekers looking for a part-time job.
} 
defined as being regularly employed, i.e. the secondary job is ignored. Regular employment is defined as employment subject to social security contributions. ${ }^{6}$ We exclude any periods without information for more than one month and treat the corresponding spells as right-censored. Missing information might be due to self-employment, employment as a civil servant, or not being available to the labour market. A further reason might be that individuals de-register as unemployment benefits elapse or are too low (compared to the administrative burden) yet still continue looking for a job. As our sample consists of prime-age men only, it is likely that individuals who are neither self-employed nor civil servants continue seeking a job independent of being registered as unemployed. ${ }^{7}$ Therefore, we examine the sensitivity of our results to this aspect in Section 5.4 and redefine uncovered periods as unemployment.

\subsection{Descriptive statistics of transition processes}

Table 1 provides the number of spells per individual spent in unemployment, in unemployment with a transition to a mini-job, and employment within our observation window. Due to the construction of our sample (inflows into unemployment) every individual has at least one unemployment spell. Almost half of all individuals have repeated unemployment spells and only a minority have five or more spells. 20,908 individuals never take up a mini-job during unemployment, and for 7,138 individuals we do not observe a transition to regular employment.

\section{[INSERT TABle 1 And Figure 1 about here]}

Figure 1 depicts the hazard rates for the transition from unemployment to regular employment, and the take-up rate of mini-jobs during unemployment. The probability of leaving unemployment for a regular job is first increasing and - after around five months - decreases with the elapsed unemployment duration. Compared to the transition from unemployment to employment the probability of entering a mini-job is rather low, and does not vary strongly according to the elapsed unemployment duration.

\footnotetext{
${ }^{6}$ We only consider employment spells with a minimum income of $13.4 € /$ day (corresponding to $400 € /$ month). Daily wages below that threshold are either due to data inconsistencies (misreported working days) or very few working hours (which is unobservable with the data at hand). Therefore, spells with an income below 400 Euro/month are right-censored (N=830).

${ }^{7}$ Transitions to self-employment and to civil service are rather rare events. For instance, the Statistic of the Federal Employment Agency reports that only $1.8 \%$ of all unemployment spells ended in self-employment in 2001. Although exits to civil service are not reported, it can be assumed that the share is even lower, given the low stock of civil servants in Germany (1.7 million civil servants in 2001 in total). This indicates that the majority of the right-censored unemployment spells ends in "inactivity" without benefit receipt, and the individuals might still search for a job.
} 


\subsection{Differences in observable characteristics}

Table 2 provides descriptive statistics measured at the initial entry into unemployment in 2001. Results are depicted for the full estimation sample, and in addition separated by those who take up a mini-job during the 36 months and those who do not.

\section{[INSERT TABLE 2 ABOUT HERE]}

Of the 24,593 drawn individuals, 3,685 take up a mini-job during unemployment within our observation window. Comparing both subgroups in column three and four suggests that the group of individuals who take up marginal employment are less likely to have a German nationality and are on average lower educated in terms of both schooling and professional training. For example, around $38 \%$ among the individuals with a mini-job have no school degree or only a lower secondary school degree combined with no professional degree, while this share is only around $27 \%$ for those without a mini-job. The sectoral distribution, the mean age, as well as the family and health situation are rather similar between both groups, as is the local labour market situation measured by unemployment rate (quarterly information) and GDP per capita (yearly basis). ${ }^{8}$

\subsection{Characteristics of mini-job spells}

In our data we have information about the sector in which individuals have regular jobs and mini-jobs. ${ }^{9}$ Table 3 displays the sectoral distribution of mini-jobs in our sample. They are primarily provided by the service and the construction sectors and this is similar among workers with different educational backgrounds, although the share of workers with a medium education taking up a mini-job in the service sector is smaller (42\%) than the corresponding shares among low and highly educated individuals (52 and $50 \%)$.

Table 4 and 5 depict a sectoral comparison of the mini-job with the previous and subsequent regular job, respectively. For instance, Table 4 shows that among all unemployed who take up a mini-job and previously worked in the construction sector, $66.3 \%$ have a mini-job in the same sector. We observe two patterns in Table 4. First, we see that many individuals take up a mini-job in the same sector in which

\footnotetext{
${ }^{8}$ Both the unemployment rate and the GDP are measured on the level of 178 employment agency districts.

${ }^{9}$ Mini-jobs in our sample have a mean (median) duration of 4.7 (3) months.
} 
they worked before entering unemployment. Second, if workers change the sector, they usually take up mini-jobs in the service sector. Table 5 suggests a strong correlation between sectors for the mini-job and the subsequent regular job. For example, $82.6 \%$ of the individuals with a mini-job in the construction sector and for whom we observe a transition into a regular job find employment in the construction sector. These numbers indicate that the mini-jobs are related to the sectoral experience and skills of the unemployed workers, which suggests that they might be relevant for the job-finding probability, for example by lowering human capital deterioration, as a screening device for potential employers or by increasing the probability of getting job offers due to network effects.

\section{[INSERT TABLE 3, 4 AND 5 ABOUt HeRE]}

Further to the finding that unemployed with a mini-job are likely to find regular employment in the same sector, we present in Table 6 the shares of individuals who find a regular job in the same firm in which they have been marginally employed. In the upper panel we consider all transitions to regular employment with a mini-job at any time before. In the lower panel we only take into account spells in which the unemployed worker was still marginally employed in the month of the exit from unemployment to employment, i.e. the individual has not left the mini-job before finding a new regular job. A large share of marginal employed individuals find a regular job within the same firm (45\%), which suggests that mini-jobs are in some cases utilized as a probation period. The share of transitions within the same firm is with $51 \%$ higher in the first 12 months of unemployment than the corresponding share after one year of unemployment (31\%). Within the group of individuals who are holding a mini-job in the month that they find a new job, the corresponding shares are slightly higher (61\% and $42 \%$, respectively).

Unemployed workers are allowed to earn up to $165 € /$ month without suffering a reduction in transfer payments. This implies that the average individual with a mini-job in our sample can increase his income during unemployment by around $23 \%$. Figure 2 depicts the income distribution of mini-jobs during unemployment and it can be seen that indeed $50 \%$ earn $163 € /$ month or less. However, there is still a large fraction of job seekers who earn more than the threshold amount. These higher earnings might be explained by labour demand side restriction, i.e., the offered jobs do not always have the exact number of working hours which would result in $165 € /$ month. This supports the idea that there exist search frictions 
in the segment of the mini-jobs. For individuals who earn more than $165 € /$ month benefit payments are reduced accordingly.

\section{[INSERT TABle 6 And Figure 2 ABOUt here]}

\section{Empirical Model}

We are interested in the differences in unemployment dynamics between job seekers with and without taking up a mini-job during their unemployment spell. Individuals can enter a mini-job at any time $t$ during their unemployment spell, and they might leave this mini-job again before leaving unemployment for a job. We do not model the duration of having a mini-job. Instead, we focus on differences in unemployment dynamics from the moment the individuals enter a mini-job onwards, independently of the duration of this mini-job.

While we do not interpret the impact of having a mini-job as a "treatment" effect, since taking up a mini-job is to a large extent the result of an individual choice, it is nonetheless important in our context to carefully model the selection into the different labour market states based on observed and unobserved characteristics. In this section we start with the presentation of a bivariate duration model for the duration until leaving unemployment for a job and the duration until entering marginal employment. This is closely related to the "timing-of-events" approach (Abbring and van den Berg, 2003). We estimate a discrete time duration model. Abbring and van den Berg (2003) provide a proof for the estimation of treatment effects in the context continuous time models. For identification in dynamic discrete models see Heckman and Navarro (2007). ${ }^{10}$ In a next step we extend this bivariate duration model by incorporating the job match quality similar to van den Berg and Vikström (2014).

Our dataset contains multiple observations for some individuals, which facilitates identification and estimation of the joint distribution of the unobserved heterogeneity variables (see e.g. Honore, 1993). Moreover, our dataset includes time-varying variables such as the local unemployment rate. Eberwein, Ham, and LaLonde (1997) and Gaure, Roed, and Zhang (2007) emphasize that time-varying covariates

\footnotetext{
${ }^{10}$ Cockx, Robin, and Goebel (2013) discuss the estimation of grouped duration data in the context of competing risks models. In our context, this issue is less relevant, since the data are grouped in intervals of one month and most of the employment spells are starting at the beginning of a month.
} 
provide exclusion restrictions because past values affect current transition probabilities only through the selection process. Brinch (2007) presents identification results that in the presence of covariates that not only vary across observations but also over time within individual observations, the mixed hazard model is non-parametrically identified with single spell duration data. In our context, the existence of multiple observations and the fact that we have time-varying covariates such as local unemployment rates make inference less sensitive to functional form assumptions.

\subsection{Durations until employment and until taking up a mini-job}

We observe labour market states in discrete time and assume that all individual differences in the probability of leaving unemployment for a job in period $t$ can be characterized by observed characteristics $x$, unobserved characteristics $V_{u}$, and whether or not a mini-job has been taken up before or at the discrete period $t$. Similarly, we assume that all individual differences in the probability of entering a mini-job in period $t$ can be characterized by observable characteristics $x$ and unobserved characteristics $V_{m}$. Given these assumptions the probability of leaving unemployment for a job $\theta_{u}(t)$ and the probability of taking up marginal employment $\theta_{m}(t)$ can be expressed by complementary log log specifications:

$$
\begin{aligned}
\theta_{u}\left(t \mid x, V_{u}, t_{m}\right) & =1-\exp \left(-\exp \left(\lambda_{t u}+x_{t}^{\prime} \beta_{u}+I\left(t \geq t_{m}\right) \delta_{u}+V_{u}\right)\right) \\
\theta_{m}\left(t \mid x, V_{m}\right) & =1-\exp \left(-\exp \left(\lambda_{t m}+x_{t}^{\prime} \beta_{m}+V_{m}\right)\right)
\end{aligned}
$$

$I(\cdot)$ takes on the value one if $t \geq t_{m}$ and $\delta_{u}$ captures the shift in the probability of finding a job after having entered a mini-job. $\lambda_{t u}$ and $\lambda_{t m}$ capture the duration dependencies. We implement this in a flexible way by including a set of dummy variables for the elapsed unemployment duration. We assume that the unobserved heterogeneity components $V_{u}$ and $V_{m}$ are constant over time, i.e. across repeated spells of unemployed individuals, and that $V_{u}$ and $V_{m}$ are uncorrelated with observed characteristics $x$.

Moreover, we assume that taking up a mini-job does not affect the probability of leaving unemployment for a job before the moment of accepting the mini-job. This assumption is referred to as the no-anticipation assumption and is very likely to hold in our application. The unemployed workers have to search for a mini-job and - similar to the transition to a regular job - the job-finding probability depends on the job offer arrival rate and the probability that the job characteristics are acceptable. It is plausible 
that vacancies of mini-jobs are usually filled at short notice, i.e., once a match between an individual looking for a mini-job and a potential employer is realized, the job starts without a (major) delay. It seems to be unlikely that an unemployed worker knows in advance the exact moment at which he will find a mini-job. Similar to the transition into temporary jobs, the worker can probably determine the rate at which a match is realized, but he cannot determine the exact timing; see Zijl, van den Berg, and Heyma (2011) for similar arguments in the context of temporary jobs and Kyyrä (2010) in the context of partial benefits for unemployed job seekers. It is important to note that the unemployed job seekers are allowed to know the probability distribution of future events conditional on observable and unobservable characteristics, which implies that the no-anticipation assumption does not rule out forward-looking behavior. Instead, the no-anticipation assumption implies that the individuals do not know the exact timing of the future event. This statement is independent of a specific underlying behavioral model. It simply ensures that individuals who have the same observed and unobserved characteristics do not change their behavior because of future realizations of transitions to mini-jobs.

\subsection{Post-unemployment outcomes}

We measure the job match quality by the monthly wage and the probability of re-entering unemployment.

We allow both outcomes to depend on unobserved characteristics which might be correlated with the unobserved factors $V_{u}$ and $V_{m}$. We assume that the unobserved heterogeneity and having taking up a mini-job have an additive impact on the mean log wage. We specify the following equation for the wage at the beginning of the new employment spell:

$$
\ln w=x_{t}^{\prime} \beta_{w}+I\left(t_{m} \leq t_{u}\right) \delta_{w}+t_{u} \eta_{w}+V_{w}+\varepsilon_{w}
$$

$\delta_{w}$ captures the difference in the mean wage between unemployed with and without a mini-job, $V_{w}$ is the unobserved heterogeneity which is assumed to be constant across repeated spells, and $\varepsilon_{w}$ is assumed to be normally distributed with mean zero and unknown variance $\sigma_{w}$. In addition, we allow the log wage to vary with respect to the previous unemployment duration $t_{u}{ }^{11}$ Part of the observed characteristics

\footnotetext{
${ }^{11}$ We define eight interval dummies to capture the previous unemployment duration. The choice of intervals is based on the observed distribution of transitions to employment (see Figure 1). We choose six intervals of two months for the first twelve months (intervals of two months) given that about $75 \%$ of all transitions take place during this period, while we have two larger intervals later on, i.e., 13-18 (19-36) months covering 15\% (10\%) of all transitions.
} 
$x_{t}$ like age and regional unemployment are measured at the first month in employment (consistent to the measurement of the first wage), while characteristics like education and health status are measured during the previous unemployment spell.

Similarly to the duration of unemployment we specify a duration of employment, described by the probability of leaving employment and re-entering unemployment in period $t$. We assume that all individual differences in the probability of re-entering unemployment in $t$ can be characterized by observed characteristics $x$, unobserved characteristics $V_{e}$ and a shift in the transition rate $\delta_{e}$ if a mini-job has been taken up in the previous unemployment spell. The probability of leaving employment in period $t$ is given by:

$$
\theta_{e}\left(t \mid x, V_{e}, t_{u}, t_{m}\right)=1-\exp \left(-\exp \left(\lambda_{t e}+x_{t}^{\prime} \beta_{e}+I\left(t_{m} \leq t_{u}\right) \delta_{e}+t_{u} \eta_{e}+V_{e}\right)\right)
$$

Similarly to the wage equation we allow $\theta_{e}$ to vary with respect to the previous unemployment duration $t_{u}$. In the empirical specification we include a set of dummy variables reflecting the previous unemployment duration in a flexible way. Some of the observed characteristics $x_{t}$ vary with $t$ like age and regional unemployment rate, while others (e.g. education and health status) are time-invariant and are measured during the previous unemployment spell. $V_{e}$ is constant over time and uncorrelated with observed characteristics $x$. However, $V_{e}$ and $V_{w}$ might be correlated with the time-varying mini-job indicator and the previous unemployment duration, which captures the dynamic selection into employment.

\subsection{Distribution of unobserved heterogeneity}

We specify the distribution of unobserved heterogeneity $G$ to have a discrete support with $P$ support points. In order to ensure that the corresponding probabilities are between zero and one and sum up to one, we use a multinomial logit parameterization of the class probabilities:

$$
\pi_{p}=\frac{\exp \left(\omega_{p}\right)}{\sum_{p=1}^{P} \exp \left(\omega_{p}\right)}, \quad p=1, \ldots, P, \quad \omega_{1}=0
$$

Each of the four components of the unobserved heterogeneity $V$ takes on a specific value at support point $p$, whereby for identification reasons the values are set to be zero for $p=1$. This implies that for a model with $P=2, G$ would be described by five parameters, for $P=3$ we estimate ten parameters, etc. This approach allows for a flexible covariance matrix for the unobserved components. For a similar model 
for unobserved heterogeneity in the context of timing-of-events models see Crepon, Ferracci, Jolivet, and van den Berg (2010) and in the context of random coefficient models in the statistical literature see e.g. Aitkin (1999). Gaure, Roed, and Zhang (2007) provide Monte Carlo evidence that modelling selection based on unobservables by a flexible discrete distribution works well in the context of timing-of-events models.

In the estimation, the model selection with respect to the "optimal" number of mass points is based on the bivariate duration model consisting of the unemployment duration and the duration until taking up a mini-job. This strategy has the advantage that the specification of the unobserved heterogeneity is based on the "timing-of-events" part of the model, which should be - as argued above - robust to functional form assumptions. We increase the number of support points until the model fit of the bivariate model cannot be further improved by an additional support point, evaluated on the basis of the Akaike Criterion (AIC) and the Bayesian Information Criterion (BIC).

\subsection{Likelihood function}

Given this setup, the likelihood contribution of an individual $i$ with one sequence $s$, i.e., one unemployment spell of length $t_{u}$ and one employment spell of length $t_{e}$, for given unobserved and observed characteristics $V$ and $x$ is given by:

$$
\begin{aligned}
L_{i s}(x, V)= & \prod_{t=1}^{t_{m}}\left[1-\theta_{m}\left(t \mid x_{i}, V_{m}\right)\right]\left(\frac{\theta_{m}\left(t_{m} \mid x_{i}, V_{m}\right)}{1-\theta_{m}\left(t_{m} \mid x_{i}, V_{m}\right)}\right)^{\kappa_{m}} \\
& \prod_{t=1}^{t_{u}}\left[1-\theta_{u}\left(t \mid x_{i}, V_{u}, t_{m}\right)\right]\left(\frac{\theta_{u}\left(t_{u} \mid x_{i}, V_{u}, t_{m}\right)}{1-\theta_{u}\left(t_{u} \mid x_{i}, V_{u}, t_{m}\right)}\right)^{\kappa_{u}} \\
& \prod_{t=t_{u}+1}^{t_{u}+t_{e}}\left[1-\theta_{e}\left(t \mid x_{i}, V_{e}, t_{u}, t_{m}\right)\right]^{\kappa_{u}}\left(\frac{\theta_{e}\left(t_{e} \mid x_{i}, V_{e}, t_{u}, t_{m}\right)}{1-\theta_{e}\left(t_{e} \mid x_{i}, V_{e}, t_{u}, t_{m}\right)}\right)^{\kappa_{u} \kappa_{e}} \\
& \left(\frac{1}{\sqrt{2 \pi \sigma^{2}}} \exp \left(-\frac{\left(\ln w_{i}-\widehat{\ln w_{i}}\right)^{2}}{2 \sigma^{2}}\right)\right)^{\kappa_{u}}
\end{aligned}
$$

The indicators $\kappa_{m}, \kappa_{u}$ and $\kappa_{e}$ take on the value one if a transition to a mini-job, to regular employment or to unemployment, respectively, is observed and zero otherwise; $\ln w_{i}$ is the logarithm of the observed wage in our data - in case we observe a transition from unemployment to a regular job - and $\widehat{\ln w_{i}}$ corresponds to the predicted value based on the coefficients $\beta_{w}$. We observe multiple spells for some individuals in our dataset. Therefore, the likelihood contribution of an individual corresponds to the 
product of the likelihood contributions of $S$ sequences of unemployment and employment spells:

$$
L_{i}(x, V)=\prod_{s=1}^{S} L_{i s}\left(x_{i}, V\right) .
$$

Since we do not know the unobserved characteristics for an individual $i$, the "unconditional" $\log$ likelihood contribution corresponds to the weighted sum of the contributions corresponding to the $P$ points of support. The log-Likelihood function for the sample with $\mathrm{N}$ individuals is given by:

$$
\ln L=\sum_{i=1}^{N} \ln \sum_{p=1}^{P} \pi_{p} L_{i}\left(x_{i}, V(p)\right) .
$$

\section{Results}

We estimate the duration until finding a mini-job, the duration of unemployment, the duration of employment and the reemployment wage with jointly distributed unobserved heterogeneity. We estimate different empirical specifications of this model. Starting with a baseline model which allows for homogeneous effects of having entered a mini-job, in a second step we introduce heterogeneity in the impact of the mini-job indicator with respect to selected observable characteristics. In a third step we estimate interaction effects of the mini-job indicator with elapsed unemployment duration. We re-estimate our model on a sample in which we re-define uncovered periods in the data as unemployment to test whether our results are robust with respect to this alternative specification of employment states. Additionally, we investigate to what extent our results are robust with respect to controlling for participation in ALMP and controlling for transitions to regular jobs within the same firm as the mini-job. Finally, we perform simulations to get insights in the extent to which marginal employment changes the expected time spent in unemployment and employment.

\subsection{Baseline results}

In Table 7 we report the coefficients of having taken up a mini-job for the different outcome equations. We control for observable characteristics as reported in Table 2 and allow for flexible duration dependencies for the duration in unemployment, the duration until entering a mini-job and the employment duration. Moreover, we control for the quarter in which the corresponding spell starts and include time-varying 
dummy indicators for the current quarter to capture seasonal effects. ${ }^{12}$ The model selection with respect to the optimal number of mass points is based on joint estimation of the parameters of the duration until taking up a mini-job and the unemployment duration as described above. In a second step, we estimate the full model including the wage equation and the employment duration using the "optimal" number of support points $P$ for each equation determined in the first step. Our final specification includes 7 mass points $(P=7)$, i.e. we estimate 30 additional parameters for the distribution of unobserved characteristics compared to a model without unobserved heterogeneity. The coefficients of the preferred model with unobserved heterogeneity are reported in the columns (2) for the unemployment duration, in column (4) for the employment duration and in column (6) for the wages in Table 7. Columns (1), (3) and (5) refer to a model without controlling for selection based on unobserved characteristics.

Commencing with column (1), we report the coefficient of the time-varying mini-job indicator for the probability of leaving unemployment for a regular job. The estimate is positive and significantly different from zero. Once we control for unobserved heterogeneity in column (2), the coefficient clearly drops and is now close to zero and no longer significantly different from zero. ${ }^{13}$ This suggests that mini-jobs are neither stepping-stones to regular jobs, nor do they lead to longer spells of unemployment. The difference between column (1) and (2) indicates a positive selection based on unobserved characteristics, i.e., conditional on observed characteristics, individuals who take up a mini-job also face a higher job finding probability.

\section{[TABLE 7 ABOUT HERE]}

Column (3) shows a positive and statistically significant effect of the mini-job dummy on employment stability in a model without unobserved heterogeneity. However, once we control for selection, the estimated parameter turns negative (and remains statistically significant) suggesting that individuals who had a mini-job during unemployment re-enter unemployment with a lower probability than individuals without a mini-job (column 4). This suggests that unemployed job seekers who take up a mini-job are individuals who have the tendency to leave unemployment quickly for rather unstable employment spells. Finally, although individuals with a mini-job face a higher employment stability, we find that they earn

\footnotetext{
${ }^{12}$ The complete set of coefficients including the distribution of the unobserved heterogeneity are available on request.

${ }^{13}$ The coefficients based on an estimation of a bivariate duration model (duration until employment and until taking up a mini-job) indicate a significant negative impact on the probability of finding a job. In the model with time-varying coefficients which are discussed in the next Section, we find the same pattern in the bivariate model and the full model. The results are available in Table B.2 in the Supplementary Appendix.
} 
significantly less than individuals without a mini-job when they take up a regular job (see column 6).

Overall, the baseline model suggests that mini-jobs during unemployment are not increasing the outflow probability from unemployment, but go along with more stable jobs, however, with lower initial wages.

\subsection{Heterogeneity with respect to observed characteristics}

To investigate effect heterogeneity we interact the mini-job indicator with selected observed characteristics. ${ }^{14}$ These characteristics include individuals' age and educational background, a dummy for having worked in the construction sector in the last regular job, and the local unemployment rate. Additionally, we include a dummy variable indicating whether or not the mini-job is in the same sector as the previous regular job. We distinguish between five sectors: construction, production, wholesale/retail, private sector services, and others. We particularly investigate the interaction effect with the construction sector, because this sector is characterized by strong seasonal employment patterns which might imply a specific role of mini-jobs for periods of unemployment. To allow for non-linear effects, we include age dummies. The estimation results are reported in Table 8. The reference person is an individual between 36 and 40 years of age, located in a region with the mean local unemployment rate, not working in the construction sector, with a medium educational background and having a mini-job in a different sector than the previous job. The coefficient of the mini-job indicator reflects the impact on job search outcomes for this reference person, and the coefficients of the interaction terms capture the heterogeneity for example with respect to the local unemployment rate or age.

\section{[TABLE 8 ABOUT HERE]}

We do not find evidence for heterogeneity for the transition probability from unemployment to regular employment with respect to age, education level, and whether or not the unemployed has worked in the construction sector before entering unemployment. For the local unemployment rate, we find evidence for a larger impact on the job finding probability in areas with high unemployment rates. However,

\footnotetext{
${ }^{14}$ We follow this strategy as separate estimations would partly suffer insufficient statistical power (due to relatively low number of observations in some subsamples). However, we test the sensitivity of our results by running separate estimations for the educational groups. We choose the educational background as this has a high economic importance and we observe a sufficiently large number of individuals in each subgroup. We find robust results which are available in Table A.1 in the Supplementary Appendix.
} 
this effect is significant only at the $10 \%$ level. Instead, we find a significantly positive coefficient for the variable indicating that the mini-job is in the same sector as the previous job. However, if we conduct a Wald-test for the significance of the overall impact - coefficient of the mini-job dummy plus coefficient of the dummy for the same sector - the test shows that this effect is not statistically significant. This suggests that having a mini-job in the same sector as the previous regular job does not have a negative impact like a mini-job in another sector, but it does not lead to a higher transition probability compared to individuals without a mini-job. A higher job finding probability for workers with a mini-job during unemployment, for example by lowering human capital deterioration, as a screening device for potential employers or by increasing the job offer arrival rate due to network effects, seems to only occur if the marginal employment is related to sectoral experience and skills of the unemployed workers. This is in line with the descriptive evidence presented above, which shows that the sector of the mini-job positively correlates with both the sector of the previous job and the sector of the post-unemployment job. However, we have to interpret this coefficient with caution, since we do not control for selection into mini-jobs in the same sector as the previous job. Instead, the estimates are based on the assumption that taking up a mini-job in the same sector is not correlated with unobserved characteristics having an impact on unemployment duration.

For the duration of employment we find a statistically significant and positive coefficient for individuals who have worked in the construction sector in the last job, and a significant negative coefficient for the interaction with the local unemployment rate. The positive effect for workers in the construction sector shows that having a mini-job during unemployment goes along with a lower employment stability compared to workers in other sectors, and the overall effect for these workers is not statistically significant. Given that employment patterns in the construction sector are heavily affected by seasonality, this evidence suggests that workers in the construction sector who are affected by unemployment (e.g. during winter months) use mini-jobs to increase their income during unemployment to bridge the time until they return to their initial employer. It seems that those workers do not use mini-jobs to actively search for new employment perspectives. The negative coefficient of the local unemployment rate suggests that holding a mini-job during unemployment is particularly beneficial when living in rather depressed regions, i.e., characterized by high unemployment rates. 
For the impact on the initial wage in a new job we also find some evidence for effect heterogeneity. While the reference person - aged between 36-40 years - who has taken-up a mini-job during unemployment already takes up jobs with lower wages, the wages are even lower for slightly younger individuals (31-35 years) with a mini-job. However, none of the other coefficients for the different age categories is statistically different from zero. Moreover, we can see a clear hierarchical order with respect to the implications of holding a mini-job during unemployment and the educational background of workers. Highly educated individuals taking up a mini-job face an even higher wage penalty compared to workers with a medium educational background, while low educated individuals face no wage difference compared to individuals without a mini-job. This indicates the existence of a stigma effect associated with mini-jobs. ${ }^{15}$ Finally, workers who took up a mini job and who have been working in the construction sector in the last job experience higher wages compared to individuals in other sectors. Therefore, our results indicate that holding a mini-job during unemployment goes along with less stable jobs but higher paid jobs for construction workers.

\subsection{Heterogeneity with respect to elapsed unemployment duration}

In Table 9 we report the coefficients of the interaction effects of the mini-job indicator with elapsed unemployment duration, allowing for different effects in months 1-2, 3-4, 5-6, 7-8, 9-10, 11-12, 13-18 and 19-36. The results suggest a significantly negative impact at the beginning of an unemployment spell. We find a significantly positive interaction effect of entering a mini-job with the elapsed unemployment duration on the probability of finding a job after seven months in unemployment (column 1). This effect size as well as the statistical significance become continuously larger suggesting a positive correlation between the impact on the job finding probability and unemployment duration. The sum of the baseline effect and the coefficient for the interaction effect is not statistically significant and close to zero in the months 7 to 12 of elapsed unemployment duration. For the months 13 to 18 a joint test indicates a statistically significant and positive effect. ${ }^{16}$ These results suggest that there exist stepping stone effects

\footnotetext{
${ }^{15}$ The impact on the initial wage for high skilled workers is rather large. Estimating separate models for the three different skill levels give a similar pattern, with highest impact for high skilled workers. However, the coefficient for the high skilled workers is much smaller, suggesting a decrease of the initial wage by $5 \%$ (see Table A.1 in the Supplementary Appendix).

${ }^{16}$ For the months 19 to 36 we get a positive point estimate, which is not statistically significant. Our sensitivity analysis based on an alternative definition of unemployment suggest that this might be driven by a relatively small number of observations, see Section 5.4 .
} 
of mini-jobs to regular jobs, but that these effects are only relevant for long-term unemployed workers.

\section{[TABLE 9 ABOUT HeRE]}

For employment stability we do not find any effect heterogeneity with respect to unemployment duration (column 2). For wages, we find some weak evidence that the mini-jobs go along with higher wages in subsequent regular employment if the mini-job was taken up earlier during the unemployment spell (see column 3).

One important determinant of the probability of leaving unemployment for a job - the receipt of unemployment benefits - depends on the elapsed unemployment duration. The maximum duration of benefit receipt depends on the time spent in regular employment in the preceding years and the age at entry into unemployment, and after benefit exhaustion unemployed job-seekers are eligible for meanstested unemployment assistance (see Section 2 for details). Due to the reduced replacement rate for unemployment assistance the income during unemployment decreases over time. However, the rules for additional earnings from marginal employment do not change, and the decrease in income is rather small. This suggests that the exhaustion of benefits cannot explain the strong evidence for time-varying coefficients of taking up marginal employment. ${ }^{17}$

Given our descriptive evidence on a decreasing share of transitions within the same firm after twelve months of unemployment, the positive impact on employment stability is probably not driven by an increasing role of mini-jobs as a probation period. We will investigate in the next section to what extent a transition from a mini-job to a regular job within the same firm correlates with a more stable employment spell. The results suggest that the positive effects of entering marginal employment - which might occur due to signaling effects, network effects, or the reduced deterioration of human capital - seem to lead to both an increase of the job-finding probability and the employment stability. The impact on the jobfinding probability seems to be less relevant at the beginning of an unemployment spell, which is plausible given that the contact frequency with former colleagues (network) and the deterioration of human capital are probably time-dependent.

\footnotetext{
${ }^{17}$ Moreover, the timing of the exhaustion of benefits varies with age at entry into unemployment and time spent in regular employment, which has a larger variation than the estimated variation in effects of having a mini-job.
} 


\subsection{Sensitivity Analysis}

Alternative definition of unemployment: We have estimated the model based on an alternative definition of unemployment. In contrast to our preferred specification, here we additionally define periods of our sample members which are not covered within the data as unemployment. This leads to longer unemployment spells and a higher number individuals taking up a mini-job. Overall, we find very similar results for this alternative definition of unemployment (see Tables A.2-A.4 in the Appendix). In the baseline model the effect of entering a mini-job on the job-finding probability is significantly positive at the $5 \%$-level (in contrast to the main sample), which is probably driven by an increasing number of observations with longer unemployment durations. In line with this, we find stronger evidence for positive interaction effects of the time-varying mini-job indicator with elapsed unemployment duration, see Table A.4. The effect measured in the baseline model reflects the average effect over the unemployment spell. Since we censor less observations in the second definition of unemployment spells, this leads to a higher weight of the impact later in the unemployment spells. Similar to the main specification, we find evidence for effect heterogeneity for the unemployment duration with respect to the sector of the mini-job and the local unemployment rate. Moreover, the negative coefficient on the interaction with the construction sector becomes statistically significant at the $5 \%$ level using the alternative sample. With respect to employment stability, we only find a significant impact of the local unemployment rate (at the $10 \%$ level), while the significance of the construction sector disappears. Similar to the main specification, we do not find any significant effects of elapsed unemployment duration. For the initial wages, the effect for the age dummy (31-35 years) is no longer significantly different from zero, while the significant effects for the educational background and the construction sector are stable. Although we observe more transitions into regular employment, especially for longer unemployment spells, again we only find weak evidence for different effects depending on the elapsed unemployment duration on initial wages.

Participation in ALMP: In our data set, we observe that individuals who take up marginal employment during unemployment have a higher probability of entering ALMP programs than unemployed individuals who do not enter a mini-job. In order to test whether our results are driven by the participation in these programs, we have re-estimated our model including time-varying indicators for the 
participation in ALMP. The results are presented in Table A.5 in the Appendix. It can be seen that the results do not change, which indicates that the impact of an increased participation in ALMP measures cannot explain our results.

Transition within same firm: The descriptive evidence reported in Table 6 suggests that some firms might use mini-jobs as a screening device; around $45 \%$ of the unemployed job seekers with a mini-job who find a regular job during our observation period take up a job at the same firm in which they had the mini-job before. In order to test in how far the job quality differs for these individuals, we interact the mini-job indicator with a variable taking on the value 1 when the individual is employed at the same firm in the regular job as before during the spell of marginal employment. The results are reported in Table A.6 in the Appendix. In the baseline specification, we find evidence that transitions within the same firm reduces employment stability compared to a job seeker who had a mini-job in a different firm. However, this interaction effect is statistically significant only at the $10 \%$ level. The significance of the minijob indicators disappears in the extended specification including interaction terms with unemployment duration. In addition to that, the results indicate that a transition within the same firm goes along with a significantly lower wage. We find that this varies with respect to the elapsed unemployment duration. The wage penalty is increasing with elapsed unemployment duration when the mini-job has been in the same firm. When interpreting these results, we have to keep in mind that we do not control for selection into regular employment spells within the same firm, i.e., our estimates might be biased if job-seekers who take up a regular job in the same firm differ in terms of unobservables from individuals who find another employer. However, this (descriptive) evidence suggests that our findings can only partly be driven by transitions within the same firm; we find significantly more stable employment spells also for individuals who find a job outside the firm at which they had a mini-job.

Transition during marginal employment: In the main analysis, the mini-job indicator takes on the value one from the moment an individual enters a mini-job onwards, independent of the duration of this mini-job. The impact of the mini-job might be different while the unemployed has a mini-job compared to periods after this mini-job ended. Therefore, we have additionally estimated a model allowing for time- 
varying effects depending on whether individuals still have a mini-job or have left this mini-job during their unemployment spell (see Table A.7 in the Appendix). Our findings suggest strong lock-in effects. Once the mini-job ended, we observe an increased job finding probability. With respect to employment stability, we do not find a different effect for individuals who still had a mini-job or not when transiting to employment. The negative wage effect seems to be stronger for individuals who accept a regular job while still having a mini-job during unemployment. However, it has to be emphasized that the coefficients have to be interpreted with caution because we do not model the endogenous duration of the mini-job.

\subsection{Simulations}

The coefficients reported in the previous sections give us insights about the direction and the relative size of the direct effects of having a mini-job on job search outcomes. In this section we perform simulations for the average unemployed worker. These simulations give us an idea about the overall difference of individuals with and without taking up a mini-job with respect to the time spent in unemployment and employment and with respect to the initial wages. Since our results indicate changing effects of having a mini-job over time, we perform simulations for a person who enters a mini-job at the beginning of the unemployment spell and for a person who enters a mini-job after one year. Our simulations are based on the model which allows for effect heterogeneity with respect to elapsed unemployment duration (Table 9). The corresponding standard errors of average state probabilities and initial wages are computed using parametric bootstrap based on 250 draws from the covariance matrix of the estimated parameters (Skrondal and Rabe-Hesketh, 2009).

We compare (i) a situation in which we assume that the unemployed worker takes up a mini-job in the first month of unemployment with (ii) a situation in which the unemployed worker never takes up a mini-job. Since our coefficients indicate a strong positive effect on the exit probability to a regular job after 12 months of unemployment, we additionally simulate the transition processes for an individual who has been unemployed for 12 months for (iii) a situation in which he has a mini-job and for (iv) a situation in which he does not have a mini-job. We calculate the average unemployment duration, the average time spent in subsequent employment and the average initial daily gross wage for regular jobs found during this period. We simulate both durations for up to 36 months, which corresponds to the maximum length 
of unemployment and employment spells in our sample. After 36 months, spells are censored. The results are reported in Table 10.

\section{[TABLE 10 ABOUT HERE]}

The results indicate that the expected time spent in unemployment does change depending on entering a mini-job already in month 1 . The difference in unemployment durations between scenarios (i) and (ii) is 1.2 months which is also statistically significant. The point estimates for the initial wages suggest slightly higher daily wages for scenario (i), which is also statistically significant. Moreover, we find a significant difference in the employment stability. While individuals without a mini-job are on average around 14.8 months in employment, individuals with a mini-job are on average 16.3 months employed after leaving the unemployment spell. In the next step, we assume that the unemployed job seekers have not found a regular job during the first 12 months of job search. In this case, the expected time spent in unemployment is significantly shorter for job-seekers holding a mini-job, which is in line with the coefficients reported in Table 9. While the unemployed worker without a mini-job spends around 16.4 additional months in unemployment, this expected time reduces to around 15.3 months for an unemployed worker with a minijob. Similar to the comparison between scenarios (i) and (ii), having a mini-job goes along with lower daily wages, where the difference is again statistically significant. Moreover, our simulations suggest that also for longer-term unemployed workers mini-jobs go along with longer subsequent employment spells; the expected time spent in employment increases from 9.7 months to 11.9 months. The difference is statistically significant.

The simulations suggest that having a mini-job goes along with more stable employment spells with initially lower wages for new entries into unemployment as well as for long-term unemployed workers. In contrast to that, having a mini-job at the beginning of the unemployment spell increases the expected unemployment duration, which implies that the negative effects at the beginning outweigh potential positive effects later, while we see a decrease in the expected unemployment duration for long-term unemployed. 


\section{Conclusions}

In many UI benefit systems unemployed workers are allowed to work for some hours and to increase their income due to earnings exemptions. In Germany, unemployed job seekers have an additional incentive due to marginal employment, which is not subject to SSC contributions by the employee. We investigate the relationship of entering marginal employment and unemployment duration and job quality of unemployed individuals and explore potential heterogeneity of this relationship with respect to observed characteristics and elapsed unemployment duration.

Based on a random inflow sample into unemployment of male workers in West Germany, our results suggest that taking up a mini-job has different implications depending on the time spent in unemployment. While we do not find any significant impact on the job finding probability in a model with homogeneous effects, models allowing for time-varying coefficients indicate a decreased job finding probability of marginal employment at the beginning of the unemployment spell and an increased job finding probability for the long-term unemployed. We find a significant increase of the transition probability to regular employment if the mini-job is in the same sector as the previous job and evidence for heterogeneity with respect to the local unemployment rate. Workers taking up a mini-job during unemployment in regions characterized by high unemployment rates face higher transition probabilities to employment and a higher employment stability. The impact on wages seems to vary with the education level and the sector. Higher educated individuals seems to experience a wage penalty when taking up a mini-job during unemployment, while low educated workers benefit in terms of wages.

We perform simulations for the average unemployed job seeker in our sample. These simulations indicate that the expected unemployment duration is significantly higher for individuals who enter a mini-job at the beginning of an unemployment spell (about 1.2 months). The employment spell is significantly longer for these workers; the expected employment duration increases from 14.8 to 16.3 months. For long-term unemployed workers having a mini-job goes along with a significantly shorter remaining unemployment duration; after one year of unemployment the remaining unemployment duration drops from 16.4 to 15.3 months.

Our descriptive analysis suggests that the positive impact on unemployment exit and employment 
stability especially for long-term unemployed workers is probably not driven by an increasing role of minijobs as a probation period. It appears more plausible that mechanisms which might be less relevant at the beginning of an unemployment spell, like the deterioration of human capital and changing networks due to changing contact frequency with colleagues, could drive these effects. Moreover, marginal employment during unemployment seems to increase the job-finding probability particularly if the mini-job is related to the sectoral experience and education of the unemployed workers. However, our analysis is based on administrative data and we do not have information about the search behaviour of unemployed individuals with and without mini-jobs, nor on the changes in human capital over time. Future research should shed more light on the underlying mechanisms which might explain the positive effect of entering marginal employment on the employment outcomes.

Our results suggest that that - at least at the individual level - earnings exemptions and mini-jobs extend the expected unemployment duration if unemployed job seekers enter a mini-job early, but that they can help long-term unemployed individuals to leave unemployment for a job. Given the high share of long-term unemployed individuals in OECD countries (approx. 35\% in 2010), it might be worth to thinking about adopting such a policy in other countries. Advantages of this instrument include that it does not involve any direct program costs, and that the administrative burden is low since the unemployed workers are searching for mini-jobs on their own. These findings are also highly relevant for the design and the timing of active labour market programs. As it is found that human capital deterioration and network effects become much more important with an increasing unemployment duration, the longterm unemployed should be primarily assigned to ALMP programs which have a strong link to the labour market, such as integration subsidies. Future research should shed some light on the interaction of marginal employment and measures such as job search assistance and training programs for unemployed workers. However, having a mini-job does not seem to have the same effect for all groups, and the results suggest that the instrument does not help to increase the job finding probabilities at the beginning of an unemployment spell.

In this paper, we carefully model the dynamic selection into the different states based on observed and unobserved (time-constant) heterogeneity. It is important to note that this approach relies on specific assumptions, and that our estimates of the relationship between having a mini-job and the job search 
outcomes are not based on any exogenous variation in the probability of entering a mini-job. Obviously, such an exogenous variation would be helpful to improve the reliability of the estimated parameters. One promising way to go in this direction could be a randomized trial with a random information treatment about the details of the earnings exemptions for some unemployed workers. However, while such an exercise would provide a causal effect, it would be identified only for a specific subgroup (the compliers). Moreover, our reduced form approach does not allow to investigate behavioral outcomes in counterfactual policies, e.g., the job search outcomes in a world without earnings exemptions for unemployed workers. This restriction would also hold for an estimation approach with a higher internal validity, like a randomized control trial. For conducting counterfactual policy analysis, one would need to conduct a structural analysis. This is beyond the focus of our paper, but clearly an interesting topic for future research. 


\section{References}

Abbring, J., and G. VAn Den Berg (2003): "The Non-Parametric Identification of Treatment Effects in Duration Models," Econometrica, 71, 1491-1517.

Aitkin, M. (1999): "A General Maximum Likelihood Analysis of Variance Components in Generalized Linear Models," Biometrics, 55(1), 117-128.

Arni, P., R. Lalive, and J. C. van Ours (2013): "How Effective Are Unemployment Benefit Sanctions? Looking Beyond Unemployment Exit," Journal of Applied Econometrics, 28, 1153-1178.

BelzIL, C. (2001): "Unemployment Insurance and Subsequent Job Duration: Job Matching vs Unobserved Heterogeneity," Journal of Applied Econometrics, 16, 619-636.

Böheim, R., And A. Weber (2011): "The Effects of Marginal Employment on Subsequent Labour Market Outcomes," German Economic Review, 12, 165-181.

Brinch, C. N. (2007): "Nonparametric Identification of the Mixed Hazards Model with Time-Varying Covariates," Econometric Theory, 23, 349-354.

Caliendo, M., and J. Hogenacker (2012): "The German Labor Market after the Great Recession: Successful Reforms and Future Challenges," IZA Journal of European Labor Studies, 1:3, 1-24.

Caliendo, M., K. Tatsiramos, and A. Uhlendorff (2013): "Benefit Duration, Unemployment Duration and Job Match Quality: A Regression-Discontinuity Approach," Journal of Applied Econometrics, $28,604-627$.

Caliendo, M., And K. Wrohlich (2010): "Evaluating the German 'Mini-Job' Reform Using a Natural Experiment," Applied Economics, 42, 2475-2489.

Card, D., R. Chetty, and A. Weber (2007): "Cash-On-Hand and competing Models of Intertemporal Behavior: New Evidence from the Labor Market," Quarterly Journal of Economics, 122, 1511-1560.

Card, D., J. Kluve, and A. Weber (2010): "Active Labor Market Policy Evaluations: A Metaanalysis," Economic Journal, 120, 452-477.

(2015): "What works? A Meta Analysis of Recent Active Labor Market Program Evaluations," IZA Discussion Paper, 9236.

Cockx, B., And M. Picchio (2012): "Are Short-Term Jobs Springboards to Long-Term Jobs? A New Approach," Oxford Bulletin of Economics and Statistics, 74, 646-675.

Cockx, B., S. R. Robin, and C. Goebel (2013): "Can income support for part-time workers serve as a stepping-stone to regular jobs? An application to young long-term unemployed women," Empirical Economics, 44, 189-229.

Crepon, B., M. Ferracci, G. Jolivet, and G. J. van den Berg (2010): "Analyzing the Anticipation of Treatments Using Data on Notification Dates," IZA Discussion Paper, 5265.

Eberle, J., And A. Schmucker (2015): "IZA/IAB Administrative Evaluation Dataset (AED) 19932010," FDZ-Datenreport 3/2015, Research Data Centre of the German Federal Employment Agency at the Institute for Employment Research.

Eberwein, C., J. HAM, And R. LALonde (1997): "The impact of being offered and receiving classroom training on the employment histories of disadvantaged women: Evidence from experimental data," Review of Economic Studies, 64, 655-682.

Ek, S., And B. Holmlund (2015): "Part-Time Unemployment and Optimal Unemployment Insurance," International Tax and Public Finance, 22(2), 201-223.

Freier, R., And V. Steiner (2008): “Marginal Employment': Stepping Stone or Dead End? Evaluating the German Experience," Zeitschrift für Arbeitsmarktforschung, 41(2/3), 223-243.

Fremigacci, F., and A. Terracol (2013): "Subsidized temporary jobs: lock-in and stepping stone effects," Applied Economics, 45, 4719-4732.

Gaure, S., K. Roed, and T. Zhang (2007): "Time and Causality: A Monte Carlo Assesment of the timing-of-events approach," Journal of Econometrics, 141, 1159-1195. 
HaAn, P. (2010): "A Multi-state Model of State Dependence in Labor Supply: Intertemporal Labor Supply Effects of a Shift from Joint to Individual Taxation," Labour Economics, 17, 323-335.

Heckman, J. J., and S. Navarro (2007): "Dynamic Discrete Choice and Dynamic Treatment Effects," Journal of Econometrics, 136, 341-396.

Honore, B. (1993): "Identification Results for Duration Models with Multiple Spells," Review of Economic Studies, 60, 241-246.

Jahn, E., And M. Rosholm (2014): "Looking Beyond the Bridge: How Temporary Agency Employment Affects Labor Market Outcomes," European Economic Review, 65, 108-125.

Kluve, J. (2010): "The Effectiveness of European Active Labor Market Programs," Labour Economics, 16, 904-918.

KYyRÄ, T. (2010): "Partial unemployment insurance benefits and the transition rate to regular work," European Economic Review, 54, 911-930.

Kyyrä, T., P. Parrotta, and M. Rosholm (2013): "The Effect of Receiving Supplementary UI Benefits on Unemployment Duration," Labour Economics, 21, 122-133.

Osikominu, A. (2013): "Quick Job Entry or Long-Term Human Capital Development? The Dynamic Effects of Alternative Training Schemes," Review of Economic Studies, 80, 313-342.

Rudolph, H. (1999): "Das 630-DM-Gesetz: Was ändert sich für wen?,” IAB-Kurzbericht, 11.

Skrondal, A., and S. Rabe-Hesketh (2009): "Prediction in multilevel generalized models," Journal of the Royal Statistical Society Series A, 172, 659-687.

Tatsiramos, K. (2009): "Unemployment Insurance in Europe: Unemployment Duration and Subsequent Employment Stability," Journal of the European Economic Association, 7, 1225-1260.

VAn den Berg, G., and J. Vikström (2014): "Monitoring Job Offer Decisions, Punishments, Exit to Work, and Job Quality," Scandinavian Journal of Economics, 116, 284-334.

VAn OuRs, J. C., AND M. Vodopivec (2008): "Does reducing unemployment insurance generosity reduce job match quality?," Journal of Public Economics, 92, 684-695.

ZiJu, M., G. J. van den Berg, and A. Heyma (2011): "Stepping Stones for the Unemployed: The Effect of Temporary Jobs on the Duration until Regular Work," Journal of Population Economics, 24, $107-139$. 
Table 1: Spells per person

\begin{tabular}{lrrr}
\hline \hline $\begin{array}{l}\text { Number } \\
\text { of Spells }\end{array}$ & Unemployment & $\begin{array}{c}\text { Mini-Job } \\
\text { (while being UE) }\end{array}$ & Employment \\
\hline 0 & - & 20,908 & 7,138 \\
1 & 13,673 & 3,270 & 9,761 \\
2 & 5,872 & 325 & 3,923 \\
3 & 3,777 & $90^{a)}$ & 3,256 \\
4 & 1,040 & $\star$ & 392 \\
$\geq 5$ & 231 & $\star$ & 123 \\
\hline \hline
\end{tabular}

Note: Depicted are the number of spells per person. For instance, 13,673 individuals have only one single unemployment spell while 231 individuals have five or more. Each column sums up to the total number of individuals $(\mathrm{N}=24,593)$.

a) Contains the number of individuals with three or more mini-job spells.

* To secure data anonymity cells with less than 20 observations are not shown.

Table 2: Descriptive statistics of observed characteristics

\begin{tabular}{|c|c|c|c|}
\hline & \multicolumn{3}{|c|}{ Estimation sample } \\
\hline & \multirow[t]{2}{*}{ Full } & \multicolumn{2}{|c|}{ Having a Mini-Job } \\
\hline & & No & Yes \\
\hline Number of individuals & 24,593 & 20,908 & 3,685 \\
\hline Age (in years) & 37.4 & 37.4 & 37.2 \\
\hline & $(8.1)$ & $(8.1)$ & $(8.1)$ \\
\hline Married & 52.7 & 52.5 & 54.2 \\
\hline Children & 33.6 & 33.3 & 34.7 \\
\hline Children $\leq 10$ years & 21.9 & 21.7 & 23.3 \\
\hline Non-German & 15.8 & 14.7 & 22.3 \\
\hline Severely handicapped & 2.0 & 2.0 & 1.8 \\
\hline Health restrictions & 12.5 & 12.0 & 15.0 \\
\hline \multicolumn{4}{|l|}{ Educational background $^{a}$ ) } \\
\hline Low & 26.8 & 24.8 & 37.7 \\
\hline Medium & 57.8 & 58.5 & 53.6 \\
\hline High & 15.5 & 16.7 & 8.7 \\
\hline \multicolumn{4}{|l|}{ Sector of last job } \\
\hline Construction & 25.3 & 25.9 & 22.3 \\
\hline Production & 21.6 & 21.6 & 21.3 \\
\hline Wholesale/Retail & 13.1 & 13.2 & 12.7 \\
\hline Private sector services & 26.7 & 25.9 & 31.7 \\
\hline Others (public sector, agriculture) & 13.3 & 13.5 & 12.0 \\
\hline \multicolumn{4}{|l|}{ Local macroeconomic conditions } \\
\hline \multirow[t]{2}{*}{ Unemployment rate (in \%) } & 7.6 & 7.5 & 8.0 \\
\hline & $(2.4)$ & $(2.4)$ & $(2.4)$ \\
\hline \multirow[t]{2}{*}{ Real GDP per capita $\left.{ }^{b}\right)$ (in thousand $€$ ) } & 28.6 & 28.7 & 28.2 \\
\hline & $(11.5)$ & $(11.7)$ & $(10.5)$ \\
\hline
\end{tabular}

Note: All statistics are percentages (if not differently indicated) and measured at entry into unemployment; standard deviations in parenthesis.

a) We aggregate information on school and professional degree to three categories capturing the educational background: (i) Low: No or only lower secondary school, and no professional degree. (ii) High: Specialized or upper secondary school, independent from professional degree. (iii) Medium: Residual group, e.g., lower or middle secondary school with an apprenticeship.

b) Normalized to prices in 2005 . 
Table 3: Sectoral distribution of mini-jobs

\begin{tabular}{lrrrr}
\hline \hline & \multirow{2}{*}{ All } & \multicolumn{3}{c}{ Educational background } \\
& & Low & Medium & High \\
& 4,198 & 1,592 & 2,264 & 342 \\
Number of spells & 19.6 & 19.8 & 21.7 & $\star$ \\
Construction & 9.7 & 8.4 & 10.3 & $\star$ \\
Production & 12.9 & 10.9 & 14.0 & 15.5 \\
Wholesale/Retail & 46.1 & 51.6 & 41.7 & 49.7 \\
Private sector services & 11.8 & 9.3 & 12.3 & 19.6 \\
Others (public sector, agriculture) & & & & \\
\hline \hline
\end{tabular}

Note: All statistics are percentages (if not differently indicated).

* To secure data anonymity cells with less than 20 observations are not shown.

Table 4: Sectoral transition matrix: From previous job to mini-job

\begin{tabular}{|c|c|c|c|c|c|}
\hline \multirow[t]{2}{*}{ Sector of previous job } & \multicolumn{5}{|c|}{ Sector of mini-job } \\
\hline & Constr. & Prod. & Retail & Services & Others \\
\hline Construction & 66.3 & 5.8 & 3.8 & 18.5 & 5.7 \\
\hline Production & 13.1 & 30.7 & 12.9 & 36.9 & 6.4 \\
\hline Wholesale/Retail & 8.3 & $\star$ & $\star$ & 38.6 & 9.5 \\
\hline Private sector services & 4.7 & 5.3 & 11.1 & 73.1 & 5.9 \\
\hline Others (public sector, agriculture) & 9.9 & $\star$ & $\star$ & 31.8 & 46.9 \\
\hline
\end{tabular}

Note: Depicted is the sectoral distribution of mini-jobs during unemployment conditional on the sector of the previous jobs; all statistics are in percentages (if not differently indicated). In total, we observe 2,206 mini-jobs ( $\mathrm{N}=1,896$ individuals). For instance, among all treated individuals who previously worked in the construction sector, $66.3 \%$ also take up a mini-job in the same sector.

* To secure data anonymity cells with less than 20 observations are not shown.

Table 5: Sectoral transition matrix: From mini-job to subsequent job

\begin{tabular}{lrrrrr}
\hline \hline \multirow{2}{*}{ Sector of mini-job } & \multicolumn{5}{c}{ Sector of subsequent job } \\
& Constr. & Prod. & Retail & Services & Others \\
\hline Construction & 82.6 & 6.4 & $\star$ & 6.4 & $\star$ \\
Production & $\star$ & $\star$ & $\star$ & 18.1 & $\star$ \\
Wholesale/Retail & $\star$ & 9.3 & 47.5 & 31.3 & $\star$ \\
Private sector services & 8.2 & 9.4 & 7.2 & 69.7 & 5.6 \\
Others (public sector, agriculture) & 12.9 & $\star$ & $\star$ & 20.4 & 57.5 \\
\hline \hline
\end{tabular}

Note: Depicted is the sectoral distribution of subsequent jobs conditional on the sector of the mini-job during unemployment; all statistics are in percentages (if not differently indicated). In total, we observe 2,206 transitions ( $\mathrm{N}=1,896$ individuals). For instance, out of all unemployed individuals who have a mini-job in the construction sector, $82.6 \%$ also find regular employment in the same sector.

* To secure data anonymity cells with less than 20 observations are not shown.

Table 6: Transition from UE (with mini-job) to RE within same firm

\begin{tabular}{crrr}
\hline \hline \multirow{2}{*}{ All } & \multicolumn{2}{c}{ Timing of transition to employment } \\
& & \multicolumn{1}{c}{$\begin{array}{c}\text { months } \\
>12 \text { months }\end{array}$} \\
\hline All transition to RE & 2,206 & 1,523 & 683 \\
Within same firm (in \%) & 44.9 & 51.1 & 31.0 \\
Direct transition to RE & 1,187 & 979 & 208 \\
Within same firm (in \%) & 57.5 & 60.8 & 41.8 \\
\hline \hline
\end{tabular}

Note: Depicted is the share of treated transitions from unemployment to employment which take place within the same firm, i.e., the mini-job during unemployment and the subsequent regular job are within the same firm. UE - Unemployment, RE - Regular employment. 
Table 7: Baseline estimation results

\begin{tabular}{|c|c|c|c|c|c|c|}
\hline & \multicolumn{2}{|c|}{ Transition UE to RE } & \multicolumn{2}{|c|}{ Transition RE to UE } & \multicolumn{2}{|c|}{ Linear wage equation } \\
\hline & (1) & $(2)$ & $(3)$ & $(4)$ & $(5)$ & $(6)$ \\
\hline Mini-Job & $\begin{array}{l}0.097^{* * *} \\
(0.023)\end{array}$ & $\begin{array}{c}0.009 \\
(0.031)\end{array}$ & $\begin{array}{l}0.099^{* * *} \\
(0.028)\end{array}$ & $\begin{array}{c}-0.137^{* * *} \\
(0.036)\end{array}$ & $\begin{array}{c}-0.092^{* * *} \\
(0.006)\end{array}$ & $\begin{array}{c}-0.027^{* * *} \\
(0.006)\end{array}$ \\
\hline Unobs. Het. $(\mathrm{P}=7)$ & No & Yes & No & Yes & No & Yes \\
\hline
\end{tabular}

Table 8: Heterogeneity with respect to observed characteristics

\begin{tabular}{|c|c|c|c|}
\hline & $\begin{array}{l}\text { Transition } \\
\text { UE to RE } \\
\text { (1) }\end{array}$ & $\begin{array}{l}\text { Transition } \\
\text { RE to UE } \\
\quad(2)\end{array}$ & $\begin{array}{c}\text { Linear wage } \\
\text { equation } \\
(3)\end{array}$ \\
\hline Mini-Job & $\begin{array}{c}-0.144^{* *} \\
(0.067)\end{array}$ & $\begin{array}{c}-0.258^{* * *} \\
(0.083)\end{array}$ & $\begin{array}{c}-0.040^{* * *} \\
(0.012)\end{array}$ \\
\hline Mini-Job $\times$ Age: $\leq 30$ years & $\begin{array}{c}0.034 \\
(0.076)\end{array}$ & $\begin{array}{c}0.080 \\
(0.096)\end{array}$ & $\begin{array}{c}0.005 \\
(0.014)\end{array}$ \\
\hline Mini-Job $\times$ Age: $31-35$ years & $\begin{array}{c}0.052 \\
(0.072)\end{array}$ & $\begin{array}{c}0.085 \\
(0.087)\end{array}$ & $\begin{array}{l}-0.032^{* * *} \\
(0.012)\end{array}$ \\
\hline Mini-Job $\times$ Age: $41-45$ years & $\begin{array}{r}-0.020 \\
(0.079)\end{array}$ & $\begin{array}{c}0.022 \\
(0.098)\end{array}$ & $\begin{array}{c}0.005 \\
(0.016)\end{array}$ \\
\hline Mini-Job $\times$ Age: $46-50$ years & $\begin{array}{c}0.011 \\
(0.088)\end{array}$ & $\begin{array}{c}0.123 \\
(0.111)\end{array}$ & $\begin{array}{c}0.010 \\
(0.016)\end{array}$ \\
\hline Mini-Job $\times$ Age: $\geq 51$ years & $\begin{array}{r}-0.127 \\
(0.097)\end{array}$ & $\begin{array}{c}-0.058 \\
(0.114)\end{array}$ & $\begin{array}{c}-0.025 \\
(0.021)\end{array}$ \\
\hline Mini-Job $\times$ Low educated & $\begin{array}{c}0.019 \\
(0.052)\end{array}$ & $\begin{array}{c}0.002 \\
(0.062)\end{array}$ & $\begin{array}{l}0.034^{* * *} \\
(0.010)\end{array}$ \\
\hline Mini-Job $\times$ High educated & $\begin{array}{c}0.010 \\
(0.094)\end{array}$ & $\begin{array}{c}-0.153 \\
(0.140)\end{array}$ & $\begin{array}{l}-0.162^{* * *} \\
(0.017)\end{array}$ \\
\hline Mini-Job $\times$ Construction & $\begin{array}{c}-0.069 \\
(0.055)\end{array}$ & $\begin{array}{l}0.145^{* *} \\
(0.066)\end{array}$ & $\begin{array}{l}0.051^{* *} \\
(0.011)\end{array}$ \\
\hline Mini-Job $\times$ Local UE-Rate & $\begin{array}{l}1.606^{*} \\
(0.997)\end{array}$ & $\begin{array}{l}-2.357^{* *} \\
(1.184)\end{array}$ & $\begin{array}{c}0.018 \\
(0.180)\end{array}$ \\
\hline Mini-Job $\times$ Same Sector & $\begin{array}{l}0.247^{* * *} \\
(0.049)\end{array}$ & $\begin{array}{c}0.061 \\
(0.059)\end{array}$ & $\begin{array}{c}0.000 \\
(0.009)\end{array}$ \\
\hline Unobs. Het. $(\mathrm{M}=7)$ & Yes & Yes & Yes \\
\hline
\end{tabular}

Note: Coefficients are statistically significant at the *10\%,**5\%,***1\% level. The estimation also includes control variables for duration dependence, seasonal dummies, individual socio-demographics, information on last job and local macroeconomic conditions. Individuals who have no school degree or graduated from the lower secondary school and do not have a professional degree (graduated from upper secondary school) are categorized as "low educated" ("high educated"). "Same sector" indicates that the mini-job was taken up within the same sector (construction, production, wholesale/retail, private sector services, others) as the last regular job. The reference person is an individual of mean age located in a region with the mean local unemployment rate, not working in the construction sector and not being unskilled. UE - Unemployment, RE - Regular employment. 
Table 9: Heterogeneity with respect to elapsed unemployment duration

\begin{tabular}{|c|c|c|c|}
\hline & $\begin{array}{c}\text { Transition UE to RE } \\
\text { (1) }\end{array}$ & $\begin{array}{c}\text { Transition RE to UE } \\
(2)\end{array}$ & $\begin{array}{c}\text { Linear wage equation } \\
(3)\end{array}$ \\
\hline Mini-Job & $\begin{array}{c}-0.239^{* * *} \\
(0.079)\end{array}$ & $\begin{array}{r}-0.118 \\
(0.110)\end{array}$ & $\begin{array}{r}-0.021 \\
(0.016)\end{array}$ \\
\hline Mini-Job $\times 3-4$ months & $\begin{array}{c}0.018 \\
(0.089)\end{array}$ & $\begin{array}{c}-0.163 \\
(0.128)\end{array}$ & $\begin{array}{r}0.034^{*} \\
(0.019)\end{array}$ \\
\hline Mini-Job $\times 5-6$ months & $\begin{array}{c}0.095 \\
(0.093)\end{array}$ & $\begin{array}{r}-0.010 \\
(0.131)\end{array}$ & $\begin{array}{r}-0.024 \\
(0.019)\end{array}$ \\
\hline Mini-Job × 7-8 months & $\begin{array}{r}0.180^{*} \\
(0.104)\end{array}$ & $\begin{array}{c}-0.031 \\
(0.138)\end{array}$ & $\begin{array}{c}0.027 \\
(0.022)\end{array}$ \\
\hline Mini-Job $\times$ 9-10 months & $\begin{array}{l}0.201^{*} \\
(0.116)\end{array}$ & $\begin{array}{r}-0.070 \\
(0.147)\end{array}$ & $\begin{array}{r}-0.037^{*} \\
(0.021)\end{array}$ \\
\hline Mini-Job $\times 11-12$ months & $\begin{array}{r}0.222^{*} \\
(0.126)\end{array}$ & $\begin{array}{r}-0.027 \\
(0.163)\end{array}$ & $\begin{array}{c}-0.034 \\
(0.023)\end{array}$ \\
\hline Mini-Job $\times 13-18$ months & $\begin{array}{l}0.444^{* * *} \\
(0.102)\end{array}$ & $\begin{array}{c}0.008 \\
(0.140)\end{array}$ & $\begin{array}{r}-0.035^{*} \\
(0.021)\end{array}$ \\
\hline Mini-Job $\times 19-36$ months & $\begin{array}{l}0.336^{* * *} \\
(0.103)\end{array}$ & $\begin{array}{r}-0.111 \\
(0.145)\end{array}$ & $\begin{array}{r}-0.034 \\
(0.021)\end{array}$ \\
\hline Unobs. Het. $(\mathrm{P}=7)$ & Yes & Yes & Yes \\
\hline
\end{tabular}

Note: Coefficients are statistically significant at the $* 10 \%,{ }^{* *} 5 \%,{ }^{* * *} 1 \%$ level. The estimation also includes control variables for duration dependence, seasonal dummies, individual socio-demographics, information on last job and local macroeconomic conditions. UE - Unemployment, RE - Regular employment.

Table 10: Simulated Durations and Initial Daily Wages

\begin{tabular}{lcccc}
\hline \hline & \multicolumn{2}{c}{ Inflow into UE } & \multicolumn{2}{c}{ After 12 months of UE } \\
& $\begin{array}{c}\text { No Mini-Job } \\
\text { (i) }\end{array}$ & $\begin{array}{c}\text { Mini-Job } \\
\text { (ii) }\end{array}$ & $\begin{array}{c}\text { No Mini-Job } \\
\text { (iii) }\end{array}$ & $\begin{array}{c}\text { Mini-Job } \\
\text { (iv) }\end{array}$ \\
\hline Unemployment Duration & 12.86 & 14.02 & 16.35 & 15.34 \\
& $(0.11)$ & $(0.35)$ & $(0.14)$ & $(0.29)$ \\
Employment Duration & 14.81 & 16.26 & 9.74 & $\begin{array}{c}11.85 \\
\text { Wages }\end{array}$ \\
& $(0.13)$ & $(0.35)$ & $(0.26)$ & $(0.48)$ \\
& 62.89 & 61.0 & 62.59 & 59.16 \\
& $(0.20)$ & $(0.41)$ & $(0.31)$ & $(0.55)$ \\
\hline \hline
\end{tabular}

Note: The simulations are based on the specification allowing for heterogeneity with respect to elapsed unemployment duration. In scenarios (i) and (ii) we simulate the outcomes from month 1 onwards. In scenarios (iii) and (iv) we assume that the individuals have been unemployed for 12 months. The reported results refer to the unemployment durations including the first 12 months. All simulations are performed for the average individual in our sample. Standard errors are computed using parametric bootstrap based on 250 draws from the covariance matrix of the estimated parameters. 


\section{Figures}

Figure 1: Hazard functions

Transition UE to RE

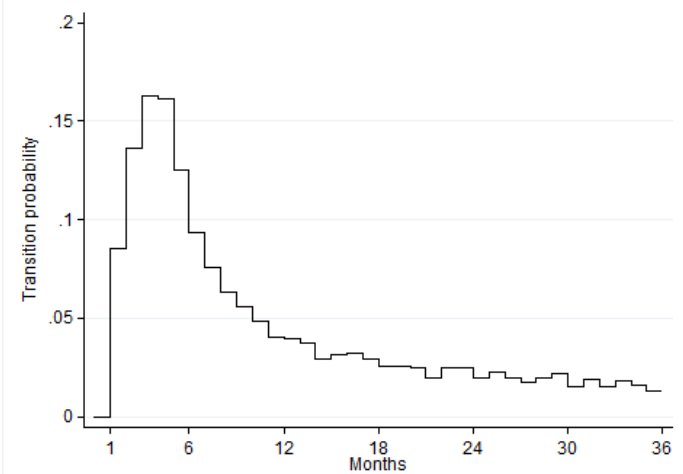

Transition UE to ME

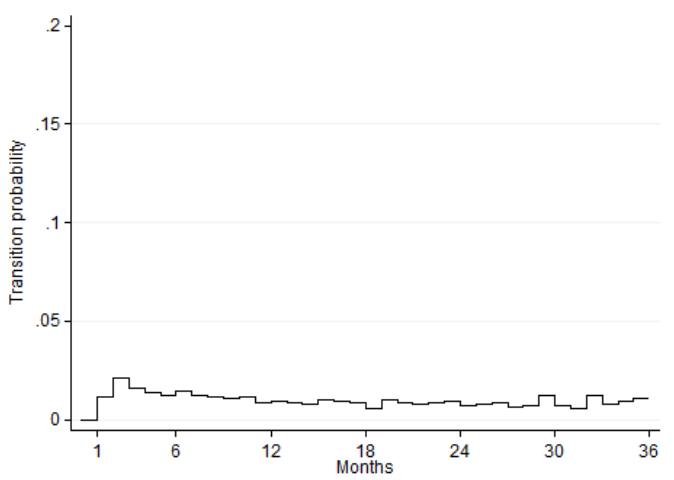

Note: Depicted are unconditional transitions probabilities. UE - Unemployment, ME - Marginal employment, RE - Regular employment.

Figure 2: Income distribution of mini-jobs during unemployment

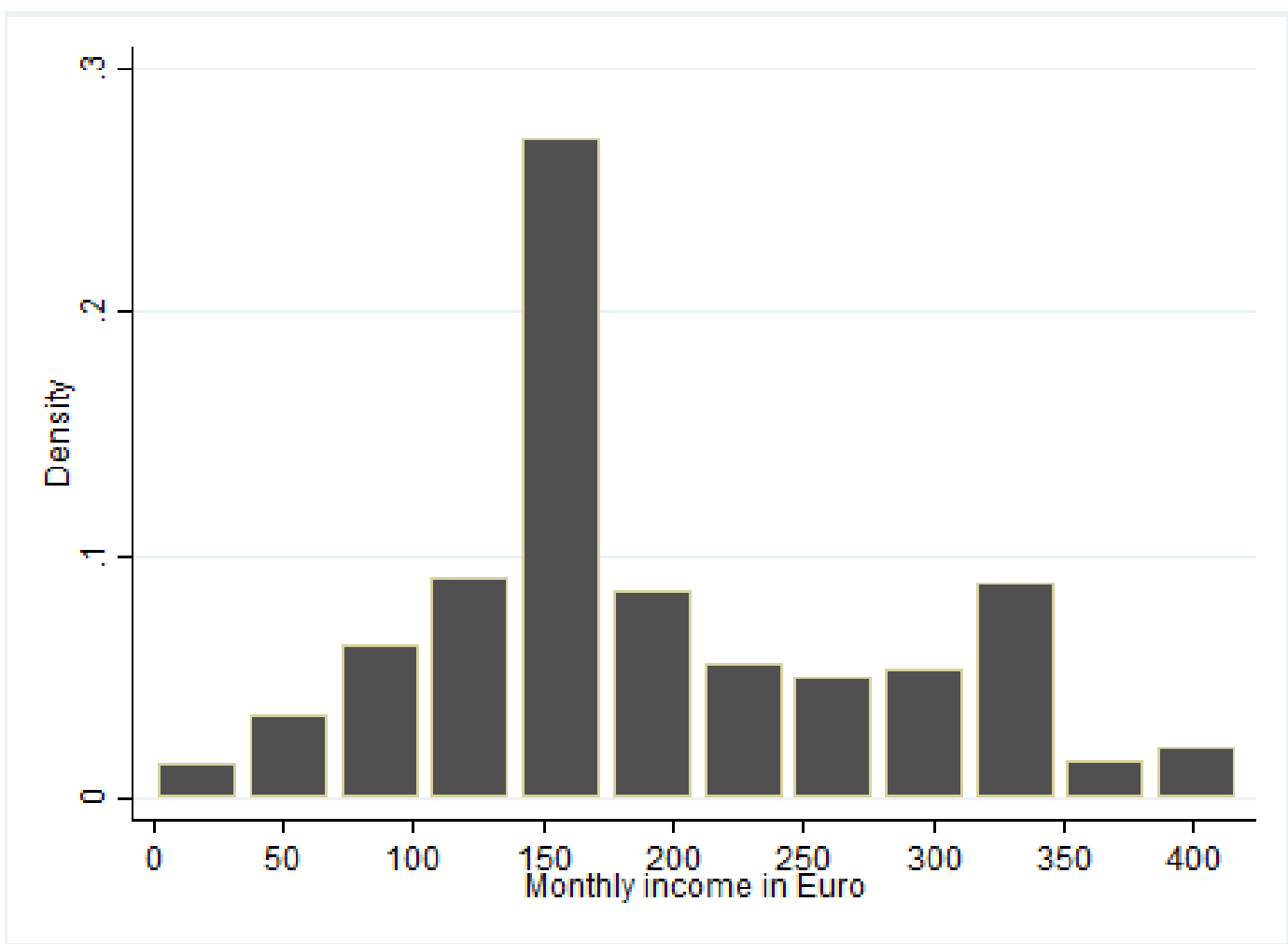

Note: The mean and median of the income distribution amount to 206 and 163 Euro per months. 


\section{A Appendix}

Table A.1: Heterogeneity with respect to educational background

\begin{tabular}{lccc}
\hline \hline & Transition UE to RE & Transition RE to UE & Linear wage equation \\
& $(1)$ & $(2)$ & $(3)$ \\
\hline Low educational background & & & \\
Mini-Job & -0.058 & $-0.145^{* *}$ & 0.000 \\
& $(0.054)$ & $(0.069)$ & $(0.010)$ \\
Unobs. Het. (P=9) & Yes & Yes & Yes \\
Number of individuals & 6,583 & 6,583 & 6,583 \\
Medium educational background & & \\
Mini-Job & -0.060 & $-0.133^{* * *}$ & $-0.012^{*}$ \\
& $(0.037)$ & $(0.048)$ & $(0.007)$ \\
Unobs. Het. (P=9) & Yes & Yes & 14,203 \\
Number of individuals & 14,203 & 14,203 & $-0.056^{*}$ \\
High educational background & & & $(0.032)$ \\
Mini-Job & 0.119 & $-0.376^{* *}$ & Yes \\
& $(0.094)$ & $(0.159)$ & 3,807 \\
Unobs. Het. (P=3) & Yes & Yes & \\
Number of individuals & 3,807 & 3,807 & \\
& & & \\
\hline \hline
\end{tabular}

Note: Coefficients are statistically significant at the * $10 \%,{ }^{* *} 5 \%, * * * 1 \%$ level. "Same sector" indicates that the mini-job was taken up within the same sector as the last regular job.

Table A.2: Alternative definition of unemployment: Baseline estimation results

\begin{tabular}{|c|c|c|c|c|c|c|}
\hline & \multicolumn{2}{|c|}{ Transition UE to RE } & \multicolumn{2}{|c|}{ Transition RE to UE } & \multicolumn{2}{|c|}{ Linear wage equation } \\
\hline & $(1)$ & $(2)$ & & $(4)$ & $(5)$ & $(6)$ \\
\hline Mini-Job & $\begin{array}{l}0.173^{* * *} \\
(0.021)\end{array}$ & $\begin{array}{l}0.117^{\text {*** }} \\
(0.029)\end{array}$ & $\begin{array}{l}0.076^{* * *} \\
(0.026)\end{array}$ & $\begin{array}{c}-0.128^{* * *} \\
(0.032)\end{array}$ & $\begin{array}{c}-0.093^{* * *} \\
(0.006)\end{array}$ & $\begin{array}{c}-0.019^{* * *} \\
(0.006)\end{array}$ \\
\hline Unobs. Het. $(\mathrm{P}=7)$ & No & Yes & No & Yes & No & Yes \\
\hline
\end{tabular}

Note: Coefficients are statistically significant at the * $10 \%,{ }^{* *} 5 \%,{ }^{* * *} 1 \%$ level. 
Table A.3: Alternative definition of unemployment: Heterogeneity with respect to observed characteristics

\begin{tabular}{|c|c|c|c|}
\hline & $\begin{array}{l}\text { Transition } \\
\text { UE to RE } \\
\text { (1) }\end{array}$ & $\begin{array}{c}\text { Transition } \\
\text { RE to UE } \\
\text { (2) }\end{array}$ & $\begin{array}{c}\text { Linear wage } \\
\text { equation } \\
(3)\end{array}$ \\
\hline Mini-Job & $\begin{array}{r}-0.029 \\
(0.062)\end{array}$ & $\begin{array}{c}-0.216^{* * *} \\
(0.075)\end{array}$ & $\begin{array}{c}-0.038^{* * *} \\
(0.013)\end{array}$ \\
\hline Mini-Job $\times$ Age: $\leq 30$ years & $\begin{array}{c}0.047 \\
(0.069)\end{array}$ & $\begin{array}{c}0.053 \\
(0.086)\end{array}$ & $\begin{array}{c}0.015 \\
(0.014)\end{array}$ \\
\hline Mini-Job $\times$ Age: $31-35$ years & $\begin{array}{c}0.091 \\
(0.066)\end{array}$ & $\begin{array}{c}0.099 \\
(0.079)\end{array}$ & $\begin{array}{c}-0.015 \\
(0.013)\end{array}$ \\
\hline Mini-Job $\times$ Age: $41-45$ years & $\begin{array}{c}0.006 \\
(0.073)\end{array}$ & $\begin{array}{c}0.014 \\
(0.090)\end{array}$ & $\begin{array}{c}0.014 \\
(0.016)\end{array}$ \\
\hline Mini-Job $\times$ Age: $46-50$ years & $\begin{array}{l}0.050 \\
(0.083)\end{array}$ & $\begin{array}{l}0.139 \\
(0.101)\end{array}$ & $\begin{array}{l}0.020 \\
(0.017)\end{array}$ \\
\hline Mini-Job $\times$ Age: $\geq 51$ years & $\begin{array}{r}-0.080 \\
(0.090)\end{array}$ & $\begin{array}{c}-0.062 \\
(0.102)\end{array}$ & $\begin{array}{c}-0.024 \\
(0.021)\end{array}$ \\
\hline Mini-Job $\times$ Low educated & $\begin{array}{c}0.019 \\
(0.048)\end{array}$ & $\begin{array}{c}-0.015 \\
(0.056)\end{array}$ & $\begin{array}{l}0.031^{* * *} \\
(0.010)\end{array}$ \\
\hline Mini-Job $\times$ High educated & $\begin{array}{c}0.014 \\
(0.083)\end{array}$ & $\begin{array}{c}-0.127 \\
(0.122)\end{array}$ & $\begin{array}{l}-0.175^{* * *} \\
(0.018)\end{array}$ \\
\hline Mini-Job $\times$ Construction & $\begin{array}{c}-0.120^{* *} \\
(0.051)\end{array}$ & $\begin{array}{c}0.078 \\
(0.061)\end{array}$ & $\begin{array}{l}0.041^{* * *} \\
(0.011)\end{array}$ \\
\hline Mini-Job $\times$ Local UE-Rate & $\begin{array}{l}1.959^{* *} \\
(0.910)\end{array}$ & $\begin{array}{r}-1.707^{*} \\
(0.977)\end{array}$ & $\begin{array}{c}0.045 \\
(0.178)\end{array}$ \\
\hline Mini-Job $\times$ Same Sector & $\begin{array}{l}0.212^{* * *} \\
(0.045)\end{array}$ & $\begin{array}{c}0.056 \\
(0.052)\end{array}$ & $\begin{array}{c}0.005 \\
(0.009)\end{array}$ \\
\hline Unobs. Het. $(\mathrm{P}=7)$ & Yes & Yes & Yes \\
\hline
\end{tabular}

Note: Coefficients are statistically significant at the * 10\%,** 5\%,*** $1 \%$ level. "Same sector" indicates that the mini-job was taken up within the same sector as the last regular job.

Table A.4: Alternative definition of unemployment: Heterogeneity with respect to elapsed unemployment duration

\begin{tabular}{lccc}
\hline \hline & Transition UE to RE & Transition RE to UE & Linear wage equation \\
& $(1)$ & $(2)$ & $(3)$ \\
\hline Mini-Job & $-0.216^{* * *}$ & -0.099 & -0.017 \\
& $(0.077)$ & $(0.103)$ & $(0.017)$ \\
Mini-Job $\times$ 3-4 months & 0.033 & -0.162 & 0.028 \\
Mini-Job $\times$ 5-6 months & $(0.087)$ & $(0.121)$ & $(0.019)$ \\
& $0.151^{*}$ & -0.046 & -0.024 \\
Mini-Job $\times$ 7-8 months & $(0.090)$ & $(0.123)$ & $(0.020)$ \\
& $0.249^{* *}$ & -0.045 & 0.011 \\
Mini-Job $\times 9-10$ months & $(0.100)$ & $(0.126)$ & $(0.023)$ \\
Mini-Job $\times 11-12$ months & $0.271^{* *}$ & -0.096 & $(0.022)$ \\
Mini-Job $\times 13-18$ months & $(0.111)$ & 0.017 & $-0.060^{* *}$ \\
Mini-Job $\times 19-36$ months & $0.321^{* * *}$ & $(0.146)$ & $(0.024)$ \\
& $(0.118)$ & -0.027 & -0.013 \\
Unobs. Het. $(\mathrm{P}=7)$ & $0.573^{* * *}$ & $(0.127)$ & $(0.021)$ \\
& $(0.095)$ & -0.127 & $(0.017$ \\
\hline \hline
\end{tabular}

Note: Depicted are estimation results using an alternative definition of unemployment.Coefficients are statistically significant at the $* 10 \%,{ }^{* *} 5 \%, * * * 1 \%$ level. 
Table A.5: Estimation including time-varying indicators for the participation in ALMP

\begin{tabular}{lccc}
\hline \hline & $\begin{array}{c}\text { Transition UE to RE } \\
(1)\end{array}$ & $\begin{array}{c}\text { Transition RE to UE } \\
(2)\end{array}$ & $\begin{array}{c}\text { Linear wage equation } \\
(3)\end{array}$ \\
& -0.023 & $-0.153^{* * *}$ & $-0.025^{* * *}$ \\
Mini-Job & $(0.031)$ & $(0.036)$ & $(0.006)$ \\
& Yes & Yes & Yes \\
Unobs. Het. $(\mathrm{P}=7)$ & & & \\
\hline
\end{tabular}

Note: Coefficients are statistically significant at the $* 10 \%, * * 5 \%, * * * 1 \%$ level. The estimation includes the usual control variables as included in the main estimation (see Table 7 ) as well as six time-varying dummies for participation in different active labor market policy programs (job creation scheme, wage subsidy, start-up subsidies, vocational training, short-term training). UE Unemployment, RE - Regular employment. 


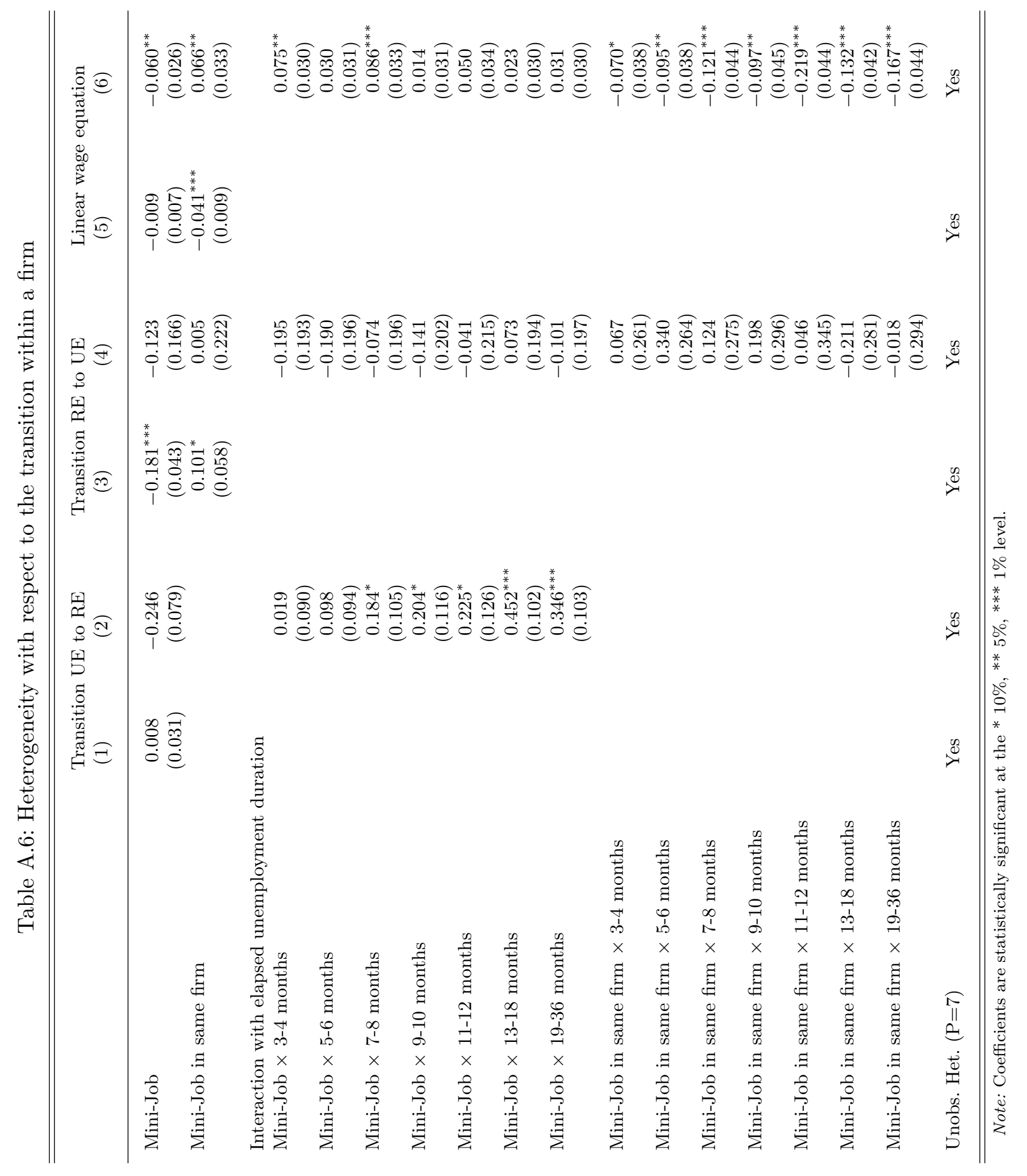


Table A.7: Estimation including a dummy for having a mini-job at transition to employment

\begin{tabular}{lccc}
\hline \hline & $\begin{array}{c}\text { Transition UE to RE } \\
(1)\end{array}$ & $\begin{array}{c}\text { Transition RE to UE } \\
(2)\end{array}$ & $\begin{array}{c}\text { Linear wage equation } \\
(3)\end{array}$ \\
\hline Mini-Job & $0.403^{* * *}$ & $-0.080^{*}$ & -0.009 \\
& $(0.037)$ & $(0.047)$ & $(0.007)$ \\
Having a mini-Job at transition & $-0.625^{* * *}$ & -0.085 & $-0.032^{* * *}$ \\
& $(0.043)$ & $(0.058)$ & $(0.009)$ \\
Unobs. Het. $(\mathrm{P}=7)$ & Yes & Yes & Yes \\
\hline
\end{tabular}

\footnotetext{
Note: "Having a mini-job at transition" indicates wether individuals still have the mini-job or not when transiting
} to employment. Coefficients are statistically significant at the ${ }^{*} 10 \%,{ }^{* *} 5 \%,{ }^{* * *} 1 \%$ level. 


\section{B Supplementary Appendix}

Table B.1: Estimation results

\begin{tabular}{|c|c|c|}
\hline & \multicolumn{2}{|l|}{$\mathrm{P}=7$} \\
\hline & Coeff. & S.E. \\
\hline Log-likelihood & \multicolumn{2}{|l|}{$-186,301$} \\
\hline Number of individuals & \multicolumn{2}{|l|}{24,593} \\
\hline \multicolumn{3}{|c|}{ Equation 1: Transition from unemployment to employment } \\
\hline Constant & $-1.988^{* * *}$ & 0.040 \\
\hline \multicolumn{3}{|l|}{ Timing of transition (Ref. 1-2 months) } \\
\hline $3-4$ months & $0.479^{* * *}$ & 0.016 \\
\hline 5-6 months & $0.181^{* * *}$ & 0.020 \\
\hline $7-8$ months & $-0.202^{* * *}$ & 0.026 \\
\hline 9-10 months & $-0.393^{* * *}$ & 0.032 \\
\hline 11-12 months & $-0.562^{* * *}$ & 0.038 \\
\hline 13-18 months & $-0.777^{* * *}$ & 0.032 \\
\hline 19-36 months & $-1.036^{* * *}$ & 0.036 \\
\hline \multicolumn{3}{|l|}{ Quarter of transition (Ref. 1st quarter) } \\
\hline 2nd quarter & $0.159^{* * *}$ & 0.015 \\
\hline 3rd quarter & $-0.034^{*}$ & 0.019 \\
\hline 4th quarter & $-0.649^{* * *}$ & 0.020 \\
\hline \multicolumn{3}{|c|}{ Quarter of entry into unemployment (Ref. 1st quarter) } \\
\hline 2nd quarter & $-0.422^{* * *}$ & 0.021 \\
\hline 3rd quarter & $-0.311^{* * *}$ & 0.021 \\
\hline 4th quarter & $-0.169^{* * *}$ & 0.016 \\
\hline \multicolumn{3}{|l|}{ Age category (Ref. $36-40$ years) } \\
\hline$\leq 30$ years & $0.089^{* * *}$ & 0.021 \\
\hline $31-35$ years & $0.036^{*}$ & 0.020 \\
\hline $41-45$ years & $-0.046^{* *}$ & 0.021 \\
\hline 46-50 years & $-0.163^{* * *}$ & 0.024 \\
\hline$\geq 51$ years & $-0.351^{* * *}$ & 0.025 \\
\hline Married & $0.131^{* * *}$ & 0.017 \\
\hline Children & $0.067^{* * *}$ & 0.023 \\
\hline Children $\leq 10$ years & $-0.063^{* * *}$ & 0.024 \\
\hline Non-German & $-0.225^{* * *}$ & 0.020 \\
\hline Severely handicapped & $-0.211^{* * *}$ & 0.055 \\
\hline Health restrictions & $-0.467^{* * *}$ & 0.023 \\
\hline \multicolumn{3}{|l|}{ Educational background (Ref. Medium) } \\
\hline Low & $-0.159^{* * *}$ & 0.016 \\
\hline High & $-0.172^{* * *}$ & 0.021 \\
\hline \multicolumn{3}{|c|}{ Sector of last job (Ref. Others (public sector, agriculture)) } \\
\hline Construction & $0.122^{* * *}$ & 0.022 \\
\hline Production & $-0.235^{* * *}$ & 0.022 \\
\hline Wholesale/Retail & $-0.246^{* * *}$ & 0.026 \\
\hline Private sector services & $-0.194^{* * *}$ & 0.021 \\
\hline \multicolumn{3}{|l|}{ Local macroeconomic conditions } \\
\hline Unemployment rate (Ref.: mean rate) & $-7.202^{* * *}$ & 0.276 \\
\hline Real GDP per capita (Ref.: mean GDP) & $-0.007^{* * *}$ & 0.001 \\
\hline Mini-Job & 0.009 & 0.031 \\
\hline
\end{tabular}

To be continued. 
Table B.1 continued.

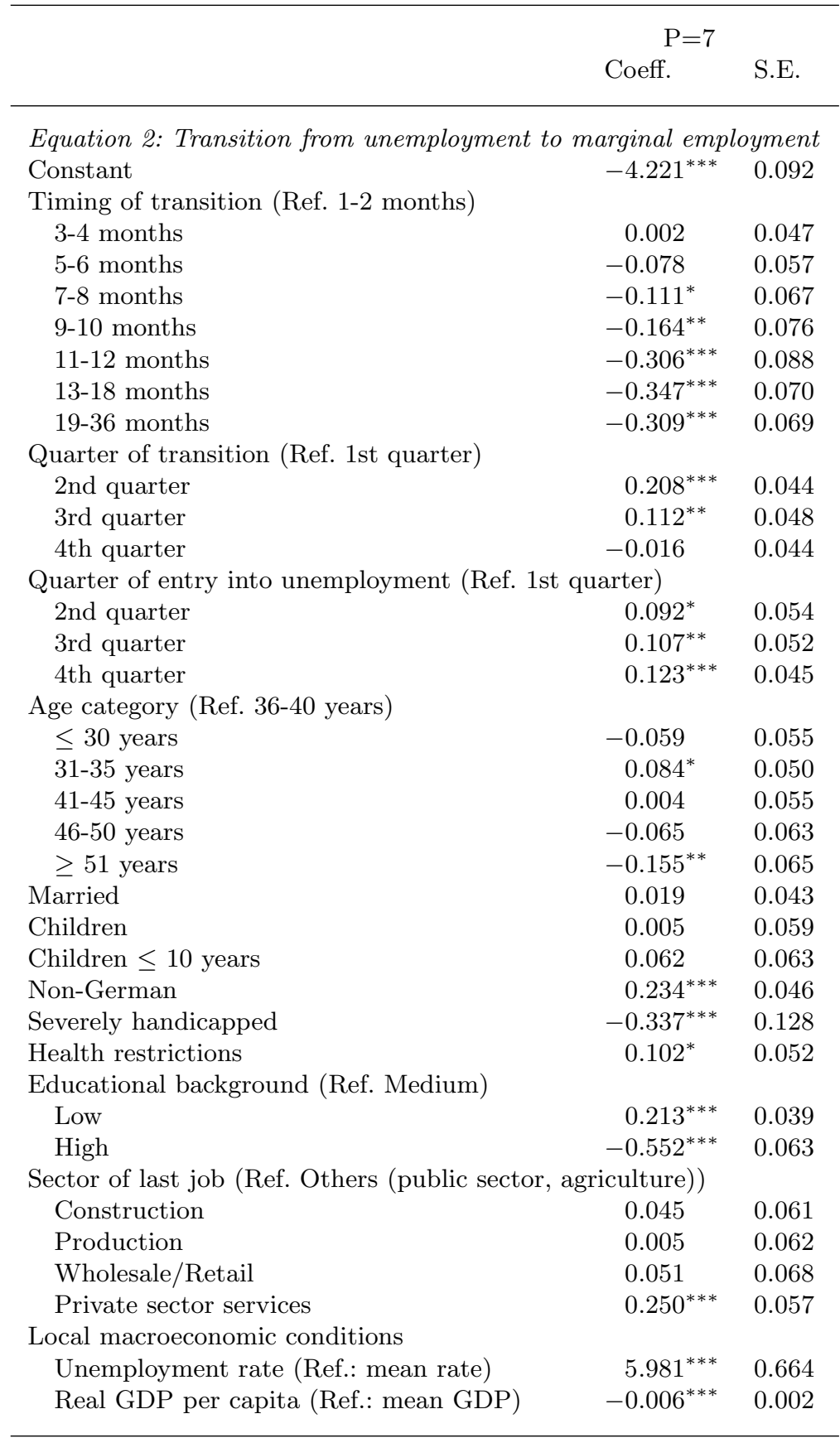

To be continued. 
Table B.1 continued.

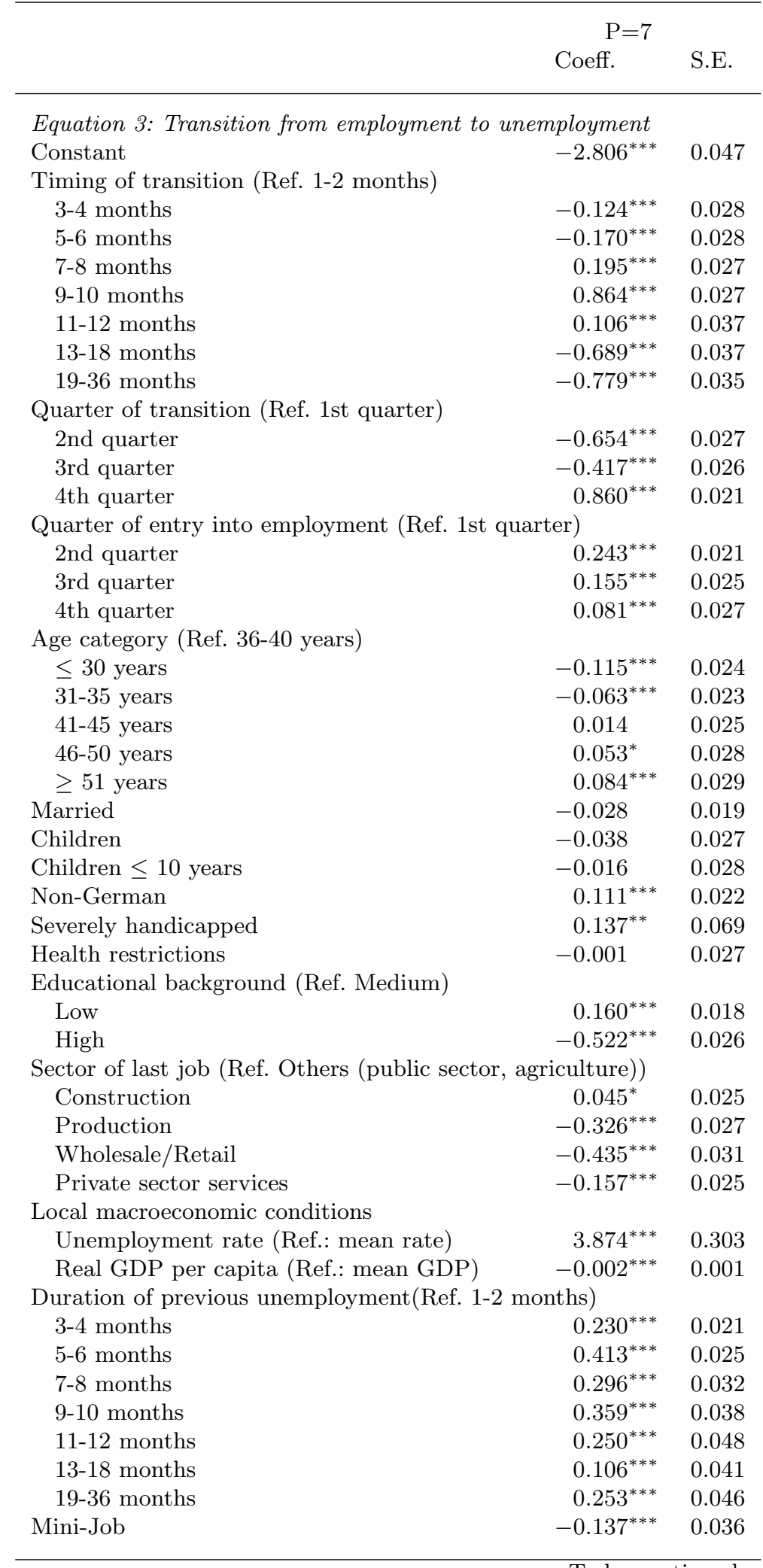

To be continued. 
Table B.1 continued.

\begin{tabular}{|c|c|c|}
\hline & \multicolumn{2}{|c|}{$\mathrm{P}=7$} \\
\hline & Coeff. & S.E. \\
\hline \multicolumn{3}{|c|}{ Equation 4: Linear wage equation (wage in first month of regular employment) } \\
\hline Constant & $3.704^{* * *}$ & 0.009 \\
\hline \multicolumn{3}{|c|}{ Quarter of entry into employment (Ref. 1st quarter) } \\
\hline 2nd quarter & $-0.015^{* * *}$ & 0.004 \\
\hline 3rd quarter & $-0.034^{* * *}$ & 0.004 \\
\hline 4th quarter & $-0.052^{* * *}$ & 0.004 \\
\hline \multicolumn{3}{|l|}{ Age category (Ref. $36-40$ years) } \\
\hline$\leq 30$ years & $-0.061^{* * *}$ & 0.005 \\
\hline$\overline{31}-35$ years & $-0.009^{*}$ & 0.005 \\
\hline 41-45 years & 0.008 & 0.005 \\
\hline $46-50$ years & $0.021^{* * *}$ & 0.006 \\
\hline$\geq 51$ years & $0.043^{* * *}$ & 0.006 \\
\hline Married & $0.027^{* * *}$ & 0.004 \\
\hline Children & $0.019^{* * *}$ & 0.006 \\
\hline Children $\leq 10$ years & $0.022^{* * *}$ & 0.006 \\
\hline Non-German & $-0.086^{* * *}$ & 0.005 \\
\hline Severely handicapped & 0.0170 .015 & \\
\hline Health restrictions & $-0.075^{* * *}$ & 0.006 \\
\hline \multicolumn{3}{|l|}{ Educational background (Ref. Medium) } \\
\hline Low & $-0.101^{* * *}$ & 0.004 \\
\hline High & $0.289^{* * *}$ & 0.005 \\
\hline \multicolumn{3}{|c|}{ Sector of last job (Ref. Others (public sector, agriculture)) } \\
\hline Construction & $0.092^{* * *}$ & 0.005 \\
\hline Production & $0.028^{* * *}$ & 0.006 \\
\hline Wholesale/Retail & 0.002 & 0.006 \\
\hline Private sector services & $-0.050^{* * *}$ & 0.005 \\
\hline \multicolumn{3}{|l|}{ Local macroeconomic conditions } \\
\hline Unemployment rate (Ref.: mean rate) & $-0.888^{* * *}$ & 0.058 \\
\hline Real GDP per capita (Ref.: mean GDP) & 0.000 & 0.000 \\
\hline \multicolumn{3}{|c|}{ Duration of previous unemployment (Ref. 1-2 months) } \\
\hline 3-4 months & 0.000 & 0.004 \\
\hline 5-6 months & $-0.017^{* * *}$ & 0.005 \\
\hline $7-8$ months & $-0.025^{* * *}$ & 0.006 \\
\hline 9-10 months & $-0.030^{* * *}$ & 0.007 \\
\hline 11-12 months & $-0.054^{* * *}$ & 0.008 \\
\hline 13-18 months & $-0.040^{* * *}$ & 0.006 \\
\hline 19-36 months & $-0.026^{* * *}$ & 0.007 \\
\hline $\operatorname{Ln}(\sigma)$ & $-1.645^{* * *}$ & 0.003 \\
\hline Mini-Job & $-0.027^{* * *}$ & 0.006 \\
\hline
\end{tabular}

To be continued. 
Table B.1 continued.

\begin{tabular}{|c|c|c|}
\hline & \multicolumn{2}{|l|}{$\mathrm{P}=7$} \\
\hline & Coeff. & S.E. \\
\hline \multicolumn{3}{|c|}{ Unobserved heterogeneity } \\
\hline$V_{u 2}$ & $-0.356^{* * *}$ & 0.090 \\
\hline$V_{u 3}$ & $-0.621^{* * *}$ & 0.052 \\
\hline$V_{u 4}$ & $0.599^{* * *}$ & 0.039 \\
\hline$V_{u 5}$ & $0.621^{* * *}$ & 0.045 \\
\hline$V_{u 6}$ & $0.303^{* * *}$ & 0.047 \\
\hline$V_{u 7}$ & $0.402^{* * *}$ & 0.066 \\
\hline$V_{m 2}$ & 0.029 & 0.128 \\
\hline$V_{m 3}$ & $-0.840^{* * *}$ & 0.094 \\
\hline$V_{m 4}$ & $-0.860^{* * *}$ & 0.099 \\
\hline$V_{m 5}$ & $-1.311^{* * *}$ & 0.188 \\
\hline$V_{m 6}$ & 0.062 & 0.091 \\
\hline$V_{m 7}$ & $2.237^{* * *}$ & 0.104 \\
\hline$V_{e 2}$ & $-0.203^{* * *}$ & 0.068 \\
\hline$V_{e 3}$ & $-0.854^{* * *}$ & 0.050 \\
\hline$V_{e 4}$ & $-0.298^{* * *}$ & 0.033 \\
\hline$V_{e 5}$ & $-0.362^{* * *}$ & 0.041 \\
\hline$V_{e 6}$ & $0.418^{* * *}$ & 0.041 \\
\hline$V_{e 7}$ & $0.163^{* *}$ & 0.080 \\
\hline$V_{w 2}$ & $-0.506^{* * *}$ & 0.010 \\
\hline$V_{w 3}$ & $0.485^{* * *}$ & 0.009 \\
\hline$V_{w 4}$ & $0.630^{* * *}$ & 0.007 \\
\hline$V_{w 5}$ & $1.042^{* * *}$ & 0.008 \\
\hline$V_{w 6}$ & $0.326^{* * *}$ & 0.007 \\
\hline$V_{w 7}$ & $0.551^{* * *}$ & 0.011 \\
\hline$\omega_{2}$ & $-1.336^{* * *}$ & 0.097 \\
\hline$\omega_{3}$ & $1.352^{* * *}$ & 0.054 \\
\hline$\omega_{4}$ & $1.217^{* * *}$ & 0.061 \\
\hline$\omega_{5}$ & $-0.658^{* * *}$ & 0.064 \\
\hline$\omega_{6}$ & $0.166^{* *}$ & 0.080 \\
\hline$\omega_{7}$ & $-1.362^{* * *}$ & 0.137 \\
\hline \multicolumn{3}{|c|}{ Correlations between unobserved terms } \\
\hline $\operatorname{Corr}\left(V_{u}, V_{m}\right)$ & 0.0848 & 0.0802 \\
\hline $\operatorname{Corr}\left(V_{u}, V_{e}\right)$ & $0.6824^{* * *}$ & 0.0278 \\
\hline $\operatorname{Corr}\left(V_{u}, V_{w}\right)$ & $0.3413^{* * *}$ & 0.0227 \\
\hline $\operatorname{Corr}\left(V_{m}, V_{e}\right)$ & $0.6172^{* * *}$ & 0.0575 \\
\hline $\operatorname{Corr}\left(V_{m}, V_{w}\right)$ & $-0.5120^{* * *}$ & 0.0362 \\
\hline $\operatorname{Corr}\left(V_{e}, V_{w}\right)$ & $-0.2736^{* * *}$ & 0.0229 \\
\hline
\end{tabular}

Note: Coefficients are statistically significant at the * $10 \%, * * 5 \%$, *** $1 \%$ level. $V_{u 2}-V_{u 7}, V_{m 2}-V_{m 7}$ and $V_{e 2}-V_{e 7}$ are the masspoints for the unemployment probability, the probability to take up a mini-job and the employment probability; $V_{w 2}-V_{w 7}$ are the masspoints for the wage equation. $\omega_{2}-\omega_{7}$ are the parameters to calculate the distribution of the masspoints as depicted in Equation 5. For identification $V_{u 1}$, $V_{m 1}, V_{e 1}, V_{w 1}$ and $\omega_{1}$ are set to be zero. 
Table B.2: Partial model: Estimation results

\begin{tabular}{|c|c|c|c|c|}
\hline & \multicolumn{2}{|c|}{$\begin{array}{l}\text { Baseline } \\
\qquad \mathrm{P}=7\end{array}$} & \multicolumn{2}{|c|}{$\begin{array}{c}\text { Interaction with } \\
\text { unemployment duration } \\
\mathrm{P}=7\end{array}$} \\
\hline & Coeff. & S.E. & Coeff. & S.E. \\
\hline Log-likelihood & \multicolumn{2}{|l|}{$-115,979$} & \multicolumn{2}{|l|}{$-115,968$} \\
\hline Number of individuals & \multicolumn{2}{|l|}{24,593} & \multicolumn{2}{|l|}{24,593} \\
\hline \multicolumn{5}{|c|}{ Equation 1: Transition from unemployment to employment } \\
\hline Constant & $-1.363^{* * *}$ & 0.106 & $-1.272^{* * *}$ & 0.117 \\
\hline \multicolumn{5}{|l|}{ Timing of transition (Ref. 1-2 months) } \\
\hline 3-4 months & $0.597^{* * *}$ & 0.016 & $0.602^{* * *}$ & 0.016 \\
\hline 5-6 months & $0.367^{* * *}$ & 0.021 & $0.369^{* * *}$ & 0.022 \\
\hline $7-8$ months & 0.025 & 0.028 & 0.020 & 0.029 \\
\hline 9-10 months & $-0.140^{* * *}$ & 0.033 & $-0.149^{* * *}$ & 0.035 \\
\hline 11-12 months & $-0.287^{* * *}$ & 0.040 & $-0.298^{* * *}$ & 0.042 \\
\hline $13-18$ months & $-0.460^{* * *}$ & 0.035 & $-0.515^{* * *}$ & 0.038 \\
\hline 19-36 months & $-0.661^{* * *}$ & 0.040 & $-0.697^{* * *}$ & 0.043 \\
\hline \multicolumn{5}{|l|}{ Quarter of transition (Ref. 1st quarter) } \\
\hline 2nd quarter & $0.189^{* * *}$ & 0.015 & $0.189^{* * *}$ & 0.015 \\
\hline 3rd quarter & 0.000 & 0.019 & 0.000 & 0.019 \\
\hline 4th quarter & $-0.632^{* * *}$ & 0.020 & $-0.632^{* * *}$ & 0.020 \\
\hline \multicolumn{5}{|c|}{ Quarter of entry into unemployment (Ref. 1st quarter) } \\
\hline 2nd quarter & $-0.475^{* * *}$ & 0.023 & $-0.474^{* * *}$ & 0.023 \\
\hline 3rd quarter & $-0.354^{* * *}$ & 0.022 & $-0.355^{* * *}$ & 0.022 \\
\hline 4th quarter & $-0.203^{* * *}$ & 0.018 & $-0.202^{* * *}$ & 0.018 \\
\hline \multicolumn{5}{|l|}{ Age category (Ref. $36-40$ years) } \\
\hline$\leq 30$ years & $0.115^{* * *}$ & 0.025 & $0.115^{* * *}$ & 0.025 \\
\hline$\overline{31}-35$ years & $0.046^{* *}$ & 0.023 & $0.046^{* *}$ & 0.023 \\
\hline 41-45 years & $-0.064^{* * *}$ & 0.025 & $-0.064^{* *}$ & 0.025 \\
\hline $46-50$ years & $-0.206^{* * *}$ & 0.028 & $-0.206^{* * *}$ & 0.028 \\
\hline$\geq 51$ years & $-0.421^{* * *}$ & 0.030 & $-0.422^{* * *}$ & 0.030 \\
\hline Married & $0.161^{* * *}$ & 0.021 & $0.162^{* * *}$ & 0.021 \\
\hline Children & $0.083^{* * *}$ & 0.028 & $0.082^{* * *}$ & 0.028 \\
\hline Children $\leq 10$ years & $-0.071^{* *}$ & 0.030 & $-0.071^{* *}$ & 0.030 \\
\hline Non-German & $-0.271^{* * *}$ & 0.025 & $-0.272^{* * *}$ & 0.025 \\
\hline Severely handicapped & $-0.235^{* * *}$ & 0.065 & $-0.235^{* * *}$ & 0.065 \\
\hline Health restrictions & $-0.552^{* * *}$ & 0.028 & $-0.551^{* * *}$ & 0.028 \\
\hline \multicolumn{5}{|l|}{ Educational background (Ref. Medium) } \\
\hline Low & $-0.195^{* * *}$ & 0.020 & $-0.195^{* * *}$ & 0.020 \\
\hline High & $-0.202^{* * *}$ & 0.025 & $-0.200^{* * *}$ & 0.025 \\
\hline \multicolumn{5}{|c|}{ Sector of last job (Ref. Others (public sector, agriculture)) } \\
\hline Construction & $0.212^{* * *}$ & 0.027 & $0.218^{* * *}$ & 0.027 \\
\hline Production & $-0.228^{* * *}$ & 0.027 & $-0.224^{* * *}$ & 0.027 \\
\hline Wholesale/Retail & $-0.232^{* * *}$ & 0.031 & $-0.228^{* * *}$ & 0.031 \\
\hline Private sector services & $-0.180^{* * *}$ & 0.026 & $-0.177^{* * *}$ & 0.026 \\
\hline \multicolumn{5}{|l|}{ Local macroeconomic conditions } \\
\hline Unemployment rate (Ref.: mean rate) & $-8.677^{* * *}$ & 0.332 & $-8.650^{* * *}$ & 0.332 \\
\hline Real GDP per capita (Ref.: mean GDP) & $-0.008^{* * *}$ & 0.001 & $-0.008^{* * *}$ & 0.001 \\
\hline Mini-Job & $-0.126^{* * *}$ & 0.036 & $-0.209^{* *}$ & 0.086 \\
\hline \multicolumn{5}{|c|}{ Interaction with timing of transition (Ref. Mini-Job $\times 1-2$ months) } \\
\hline Mini-Job $\times 3-4$ months & & & -0.036 & 0.092 \\
\hline Mini-Job $\times 5-6$ months & & & 0.029 & 0.099 \\
\hline Mini-Job $\times 7-8$ months & & & 0.103 & 0.110 \\
\hline Mini-Job $\times 9$-10 months & & & 0.122 & 0.121 \\
\hline Mini-Job $\times 11-12$ months & & & 0.135 & 0.131 \\
\hline Mini-Job $\times 13-18$ months & & & $0.345^{* * *}$ & 0.108 \\
\hline Mini-Job $\times 19-36$ months & & & $0.196^{*}$ & 0.113 \\
\hline
\end{tabular}


Table B.2 continued.

\begin{tabular}{|c|c|c|c|c|}
\hline & \multicolumn{2}{|l|}{ Baseline } & \multicolumn{2}{|c|}{$\begin{array}{l}\text { Interaction with } \\
\text { unemployment duration } \\
\mathrm{P}=7\end{array}$} \\
\hline & Coeff. & S.E. & Coeff. & S.E. \\
\hline \multicolumn{5}{|c|}{ Equation 2: Transition from unemployment to marginal employment } \\
\hline Constant & $-1.632^{* * *}$ & 0.174 & $-1.648^{* * *}$ & 0.171 \\
\hline \multicolumn{5}{|l|}{ Timing of transition (Ref. 1-2 months) } \\
\hline 3-4 months & 0.076 & 0.048 & $0.080^{*}$ & 0.048 \\
\hline 5-6 months & 0.058 & 0.060 & 0.060 & 0.060 \\
\hline 7-8 months & 0.064 & 0.071 & 0.060 & 0.071 \\
\hline 9-10 months & 0.045 & 0.080 & 0.034 & 0.080 \\
\hline 11-12 months & -0.067 & 0.092 & -0.081 & 0.092 \\
\hline 13-18 months & -0.060 & 0.078 & -0.087 & 0.078 \\
\hline 19-36 months & 0.086 & 0.089 & 0.031 & 0.090 \\
\hline \multicolumn{5}{|l|}{ Quarter of transition (Ref. 1st quarter) } \\
\hline 2nd quarter & $0.232^{* * *}$ & 0.045 & $0.234^{* * *}$ & 0.045 \\
\hline 3rd quarter & $0.145^{* * *}$ & 0.048 & $0.144^{* * *}$ & 0.048 \\
\hline 4th quarter & 0.010 & 0.045 & 0.009 & 0.045 \\
\hline \multicolumn{5}{|c|}{ Quarter of entry into unemployment (Ref. 1st quarter) } \\
\hline 2nd quarter & 0.091 & 0.058 & $0.101^{*}$ & 0.058 \\
\hline 3rd quarter & $0.105^{*}$ & 0.056 & $0.116^{* *}$ & 0.056 \\
\hline 4th quarter & $0.127^{* * *}$ & 0.048 & $0.134^{* * *}$ & 0.048 \\
\hline \multicolumn{5}{|l|}{ Age category (Ref. $36-40$ years) } \\
\hline$\leq 30$ years & -0.051 & 0.063 & -0.047 & 0.062 \\
\hline $31-35$ years & $0.103^{*}$ & 0.056 & $0.104^{*}$ & 0.055 \\
\hline $41-45$ years & 0.004 & 0.061 & 0.005 & 0.060 \\
\hline $46-50$ years & -0.106 & 0.070 & -0.104 & 0.069 \\
\hline$\geq 51$ years & $-0.202^{* * *}$ & 0.073 & $-0.202^{* * *}$ & 0.073 \\
\hline Married & 0.030 & 0.050 & 0.031 & 0.049 \\
\hline Children & 0.012 & 0.068 & 0.012 & 0.067 \\
\hline Children $\leq 10$ years & 0.065 & 0.072 & 0.061 & 0.071 \\
\hline Non-German & $0.237^{* * *}$ & 0.055 & $0.240^{* * *}$ & 0.055 \\
\hline Severely handicapped & $-0.394^{* * *}$ & 0.143 & $-0.391^{* * *}$ & 0.143 \\
\hline Health restrictions & 0.085 & 0.061 & 0.090 & 0.061 \\
\hline \multicolumn{5}{|l|}{ Educational background (Ref. Medium) } \\
\hline Low & $0.236^{* * *}$ & 0.046 & $0.238^{* * *}$ & 0.046 \\
\hline High & $-0.610^{* * *}$ & 0.070 & $-0.602^{* * *}$ & 0.070 \\
\hline \multicolumn{5}{|c|}{ Sector of last job (Ref. Others (public sector, agriculture)) } \\
\hline Construction & 0.031 & 0.069 & 0.045 & 0.069 \\
\hline Production & -0.044 & 0.071 & -0.031 & 0.070 \\
\hline Wholesale/Retail & 0.032 & 0.078 & 0.045 & 0.077 \\
\hline Private sector services & $0.268^{* * *}$ & 0.066 & $0.277^{* * *}$ & 0.065 \\
\hline \multicolumn{5}{|l|}{ Local macroeconomic conditions } \\
\hline Unemployment rate (Ref.: mean rate) & $6.362^{* * *}$ & 0.753 & $6.418^{* * *}$ & 0.748 \\
\hline Real GDP per capita (Ref.: mean GDP) & $-0.006^{* * *}$ & 0.002 & $-0.006^{* * *}$ & 0.002 \\
\hline
\end{tabular}

To be continued. 
Table B.2 continued.

\begin{tabular}{lcccc}
\hline & Baseline & & \multicolumn{2}{c}{$\begin{array}{c}\text { Interaction with } \\
\text { unemployment duration }\end{array}$} \\
& $\begin{array}{c}\mathrm{P}=7 \\
\text { Coeff. }\end{array}$ & S.E. & Coeff. & S.E. \\
\hline & & & & \\
Unobserved heterogeneity & & & $-2.073^{* * *}$ & 0.261 \\
$V_{u 2}$ & $-2.045^{* * *}$ & 0.293 & $1.217^{* * *}$ & 0.191 \\
$V_{u 3}$ & $1.314^{* * *}$ & 0.185 & -0.349 & 0.267 \\
$V_{u 4}$ & -0.187 & 0.255 & $-1.008^{* * *}$ & 0.266 \\
$V_{u 5}$ & $-0.942^{* * *}$ & 0.305 & $-0.799^{* * *}$ & 0.227 \\
$V_{u 6}$ & $-0.683^{* * *}$ & 0.199 & 0.112 & 0.229 \\
$V_{u 7}$ & 0.238 & 0.287 & $-4.141^{* * *}$ & 0.435 \\
$V_{m 2}$ & $-4.361^{* * *}$ & 0.496 & $-4.091^{* * *}$ & 1.091 \\
$V_{m 3}$ & $-4.227^{* * *}$ & 1.169 & -8.718 & 130.370 \\
$V_{m 4}$ & -5.458 & 5.693 & $-3.000^{* * *}$ & 0.570 \\
$V_{m 5}$ & $-3.146^{* * *}$ & 0.599 & $-1.388^{* *}$ & 0.643 \\
$V_{m 6}$ & $-1.578^{* * *}$ & 0.574 & $-2.687^{* * *}$ & 0.447 \\
$V_{m 7}$ & $-2.639^{* * *}$ & 0.604 & $2.498^{* * *}$ & 0.504 \\
$\omega_{2}$ & $2.396^{* * *}$ & 0.573 & 0.303 & 0.486 \\
$\omega_{3}$ & 0.266 & 0.494 & $2.568^{* * *}$ & 0.782 \\
$\omega_{4}$ & $2.588^{* * *}$ & 0.812 & $3.040^{* * *}$ & 0.454 \\
$\omega_{5}$ & $3.014^{* * *}$ & 0.495 & 1.173 & 1.160 \\
$\omega_{6}$ & 1.546 & 1.077 & $2.184^{* * *}$ & 0.698 \\
$\omega_{7}$ & $1.958^{*}$ & 1.063 & &
\end{tabular}

Note: Coefficients are statistically significant at the ${ }^{*} 10 \%,{ }^{* *} 5 \%,{ }^{* * *} 1 \%$ level. $V_{u 2}-V_{u 7}$ and $V_{m 2^{-}}$ $V_{m 7}$ are the masspoints for the unemployment probability and the probability to take up a mini-job . $\omega_{2}-\omega_{7}$ are the parameters to calculate the distribution of the masspoints as depicted in Equation 5. For identification $V_{u 1}, V_{m 1}$ and $\omega_{1}$ are set to be zero. 